\title{
Supporting Information: Experimental Validation of Mass \\ Balance Models for in vitro Cell-based Bioassays
}

Luise Henneberger, ${ }^{\dagger, \star}$ Marie Mühlenbrink, ${ }^{\dagger}$ Daniel J. Heinrich, ${ }^{*}$ Alexandre Teixeira, ${ }^{\S}$ Beate Nicol, ${ }^{\S}$ Beate I. Escher ${ }^{\dagger, \#}$

${ }^{+}$Helmholtz Centre for Environmental Research - UFZ, Department of Cell Toxicology, Permoserstr. 15, 04318 Leipzig, Germany

\# Eberhard Karls University Tübingen, Environmental Toxicology, Center for Applied Geoscience, 72074 Tübingen, Germany

$\S$ Safety \& Environmental Assurance Centre, Colworth Science Park, Sharnbrook, Bedfordshire MK44 1LQ, UK

Corresponding author

*Address: Helmholtz Centre for Environmental Research GmbH - UFZ, Department of Cell Toxicology, Permoserstraße 15, 04318 Leipzig, Germany, Phone +49 341235 1092, E-mail: luise.henneberger@ufz.de.

S1. Test chemicals and experimental parameters

S2. Instrumental analysis

S3. Kinetics of fiber uptake

S4. Comparison of equilibration times and fiber-water distribution ratios

S5. Comparison of fiber-water, BSA-water, liposome-water, FBS-water and cellwater distribution ratios with octanol-water partition constants

S6. Fiber sorption isotherms

S7. Comparison of BSA-water and liposome-water distribution ratios

S8. FBS sorption isotherms

S9. Estimation of protein saturation

S10. Cell-water distribution ratios and ANOVA test

S11. Prediction of cell-water distribution using structural proteins as surrogate for cellular proteins 


\section{S1. Test chemicals and experimental parameters}

Table S1. Properties (acidity constant $\left(\mathrm{p} K_{\mathrm{a}}\right)$, octanol-water partition constant $\left(K_{\mathrm{ow}}\right)$, water-air partition constant $\left(K_{\mathrm{wa}}\right)$ and medium-air partition constant $\left.\left(K_{\text {medium/air }}\right)\right)$ of the test chemicals and experimental conditions for the solid-phase microextraction experiments.

\begin{tabular}{|c|c|c|c|c|c|c|c|c|c|c|}
\hline Chemical & CAS No. & Supplier & Chemical class & $\mathrm{p} K_{\mathrm{a}}$ & $\log K_{\text {ow }}$ & $\log K_{w a}$ & $\begin{array}{c}\log \\
K_{\text {medium/air }}\end{array}$ & $\begin{array}{c}\text { SPME } \\
\text { fiber }\end{array}$ & $\begin{array}{c}\text { desorption } \\
\text { solution }\end{array}$ & $\begin{array}{c}\text { shaker } \\
\text { (rpm) }\end{array}$ \\
\hline \multicolumn{11}{|l|}{ Neutral chemicals } \\
\hline benzo[a]pyrene & $50-32-8$ & Sigma-Aldrich & $\begin{array}{c}\text { neutral } \\
\text { superhydrophobic }\end{array}$ & - & $6.13^{a}$ & $6.18^{\mathrm{e}}$ & $9.54^{p}$ & PDMS & $\mathrm{ACN}$ & $\begin{array}{l}\text { vortex } \\
(1200)\end{array}$ \\
\hline benzo[k]fluoranthene & $207-08-9$ & Supelco & $\begin{array}{c}\text { neutral } \\
\text { superhydrophobic }\end{array}$ & - & $6.11^{a}$ & $5.27^{e}$ & $8.47^{p}$ & PDMS & $\mathrm{ACN}$ & $\begin{array}{l}\text { vortex } \\
(1200)\end{array}$ \\
\hline bisphenol A & $80-05-7$ & Sigma-Aldrich & neutral hydrophobic & $9.59^{b}$ & $3.32^{a}$ & $9.59^{e}$ & $10.43^{p}$ & C18 & $\begin{array}{c}\mathrm{ACN} / \mathrm{H}_{2} \mathrm{O} \\
90 / 10\end{array}$ & $\begin{array}{l}\text { vortex } \\
(1200)\end{array}$ \\
\hline quinoxyfen & $124495-18-7$ & Sigma-Aldrich & neutral hydrophobic & $3.56^{c}$ & $4.66^{a}$ & $4.50^{e}$ & $6.42^{p}$ & C18 & $\begin{array}{c}\mathrm{ACN} / \mathrm{H}_{2} \mathrm{O} \\
90 / 10\end{array}$ & $\begin{array}{l}\text { vortex } \\
(1200)\end{array}$ \\
\hline triclocarban & $101-20-2$ & Sigma-Aldrich & neutral hydrophobic & $12.7^{d}$ & $5.43^{e}$ & $7.28^{\mathrm{e}}$ & $10.05^{p}$ & C18 & $\begin{array}{c}\mathrm{ACN} / \mathrm{H}_{2} \mathrm{O} \\
90 / 10\end{array}$ & $\begin{array}{l}\text { vortex } \\
(1200)\end{array}$ \\
\hline fluoranthene & $206-44-0$ & Sigma-Aldrich & neutral hydrophobic & - & $5.16^{a}$ & $3.83^{e}$ & $6.08^{p}$ & C18 & $\mathrm{ACN}$ & $\begin{array}{l}\text { vortex } \\
(1200)\end{array}$ \\
\hline 6-gingerol & $23513-14-6$ & Sigma-Aldrich & neutral hydrophobic & $9.7^{f}$ & $3.01^{e}$ & $10.18^{e}$ & $11.07^{p}$ & C18 & $\mathrm{ACN}$ & $\begin{array}{l}\text { orbital } \\
(250)\end{array}$ \\
\hline 8-gingerol & $23513-08-8$ & Sigma-Aldrich & neutral hydrophobic & $9.7^{f}$ & $4.08^{\mathrm{e}}$ & $9.91^{\mathrm{e}}$ & $11.53^{p}$ & C18 & $\mathrm{ACN}$ & $\begin{array}{l}\text { orbital } \\
(250)\end{array}$ \\
\hline caffeine & $58-08-2$ & Sigma-Aldrich & neutral hydrophilic & - & $-0.07^{a}$ & $8.66^{e}$ & $8.75^{p}$ & C18 & $\begin{array}{c}\mathrm{ACN} / \mathrm{H}_{2} \mathrm{O} \\
10 / 90\end{array}$ & $\begin{array}{l}\text { orbital } \\
(250)\end{array}$ \\
\hline coumarin & $91-64-5$ & Sigma-Aldrich & neutral hydrophilic & - & $1.39^{a}$ & $5.21^{\mathrm{e}}$ & $5.42^{p}$ & C18 & $\begin{array}{c}\mathrm{ACN} / \mathrm{H}_{2} \mathrm{O} \\
90 / 10\end{array}$ & $\begin{array}{l}\text { orbital } \\
(250)\end{array}$ \\
\hline zingerone & $122-48-5$ & Sigma-Aldrich & neutral hydrophilic & $9.7^{f}$ & $1.39^{e}$ & $7.06^{\mathrm{e}}$ & $7.51^{\mathrm{p}}$ & C18 & $\begin{array}{c}\mathrm{ACN} / \mathrm{H}_{2} \mathrm{O} \\
90 / 10\end{array}$ & $\begin{array}{l}\text { orbital } \\
(250)\end{array}$ \\
\hline lamotrigine & 84057-84-1 & $\begin{array}{c}\text { Cayman Chemical } \\
\text { Company }\end{array}$ & neutral hydrophilic & $5.34^{g}$ & $2.57^{a}$ & $9.32^{\mathrm{e}}$ & $9.57^{p}$ & C18 & $\begin{array}{c}\mathrm{ACN} / \mathrm{H}_{2} \mathrm{O} \\
50 / 50 \\
\end{array}$ & $\begin{array}{l}\text { orbital } \\
(250)\end{array}$ \\
\hline \multicolumn{11}{|l|}{ Ionizable chemicals } \\
\hline metoprolol & $37350-58-6$ & Sigma-Aldrich & base & $9.68^{h}$ & - & - & - & C18 & $\begin{array}{c}\mathrm{ACN} / \mathrm{H}_{2} \mathrm{O} \\
90 / 10^{i}\end{array}$ & $\begin{array}{l}\text { Orbital } \\
(250)\end{array}$ \\
\hline propranolol & $525-66-6$ & Sigma-Aldrich & base & $9.42^{\mathrm{a}}$ & - & - & - & C18 & $\begin{array}{c}\mathrm{ACN} / \mathrm{H}_{2} \mathrm{O} \\
90 / 10^{\mathrm{i}}\end{array}$ & $\begin{array}{l}\text { orbital } \\
(250)\end{array}$ \\
\hline diphenhydramine & $58-73-1$ & Sigma-Aldrich & base & $8.98^{a}$ & - & - & - & C18 & $\begin{array}{c}\mathrm{ACN} / \mathrm{H}_{2} \mathrm{O} \\
90 / 10^{\mathrm{i}}\end{array}$ & $\begin{array}{l}\text { orbital } \\
(250)\end{array}$ \\
\hline
\end{tabular}


Table S1. continued.

\begin{tabular}{|c|c|c|c|c|c|c|c|c|c|c|}
\hline venlafaxine & $93413-69-5$ & LKT Laboratories & base & $8.4^{\mathrm{e}}$ & - & - & - & C18 & $\begin{array}{c}\mathrm{ACN} / \mathrm{H}_{2} \mathrm{O} \\
90 / 10^{\mathrm{i}}\end{array}$ & $\begin{array}{c}\text { orbital } \\
(250)\end{array}$ \\
\hline diclofenac & $15307-86-5$ & $\begin{array}{c}\text { Cayman Chemical } \\
\text { Company }\end{array}$ & acid & $4.15^{\mathrm{a}}$ & - & - & - & C18 & $\begin{array}{c}\mathrm{ACN} / \mathrm{H}_{2} \mathrm{O} \\
90 / 10\end{array}$ & $\begin{array}{c}\text { orbital } \\
(250)\end{array}$ \\
\hline $2,4-D$ & $94-75-7$ & $\begin{array}{c}\text { Cayman Chemical } \\
\text { Company }\end{array}$ & acid & $2.9^{j}$ & - & - & - & C18 & $\begin{array}{c}\mathrm{MeOH} / \mathrm{H}_{2} \mathrm{O} \\
50 / 50\end{array}$ & $\begin{array}{l}\text { orbital } \\
(250)\end{array}$ \\
\hline ibuprofen & $15687-27-1$ & Sigma-Aldrich & acid & $4.45^{\mathrm{k}}$ & - & - & - & C18 & $\begin{array}{c}\mathrm{MeOH} / \mathrm{H}_{2} \mathrm{O} \\
50 / 50\end{array}$ & $\begin{array}{c}\text { orbital } \\
(250)\end{array}$ \\
\hline naproxen & $22204-53-1$ & $\begin{array}{c}\text { Cayman Chemical } \\
\text { Company }\end{array}$ & acid & $4.15^{\mathrm{a}}$ & - & - & - & C18 & $\begin{array}{c}\mathrm{MeOH} / \mathrm{H}_{2} \mathrm{O} \\
50 / 50\end{array}$ & $\begin{array}{l}\text { orbital } \\
(250)\end{array}$ \\
\hline torasemide & $56211-40-6$ & Sigma-Aldrich & acid & $6.68^{1}$ & - & - & - & C18 & $\begin{array}{c}\mathrm{MeOH} / \mathrm{H}_{2} \mathrm{O} \\
50 / 50\end{array}$ & $\begin{array}{c}\text { orbital } \\
(250)\end{array}$ \\
\hline warfarin & $81-81-2$ & Fluka & acid & $4.9^{\mathrm{m}}$ & - & - & - & C18 & $\begin{array}{c}\mathrm{MeOH} / \mathrm{H}_{2} \mathrm{O} \\
50 / 50\end{array}$ & $\begin{array}{l}\text { orbital } \\
(250)\end{array}$ \\
\hline genistein & $446-72-0$ & $\begin{array}{c}\text { Cayman Chemical } \\
\text { Company }\end{array}$ & acid & $\begin{array}{c}7.2,10 \\
13.1^{\mathrm{n}}\end{array}$ & - & - & - & C18 & $\begin{array}{c}\mathrm{ACN} / \mathrm{H}_{2} \mathrm{O} \\
90 / 10\end{array}$ & $\begin{array}{c}\text { orbital } \\
(250)\end{array}$ \\
\hline labetalol & $36894-69-6$ & Sigma-Aldrich & complex speciation & $\begin{array}{l}7.35 \\
9.11^{\circ}\end{array}$ & - & - & - & C18 & $\begin{array}{c}\mathrm{ACN} / \mathrm{H}_{2} \mathrm{O} \\
90 / 10^{\mathrm{i}}\end{array}$ & $\begin{array}{l}\text { orbital } \\
(250)\end{array}$ \\
\hline
\end{tabular}

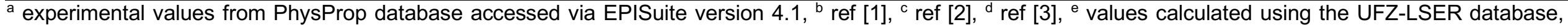

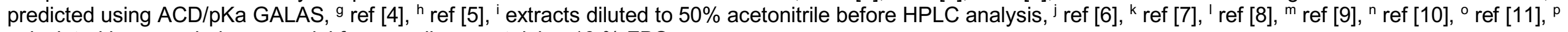
calculated by mass balance model for a medium containing $10 \%$ FBS 
Table S2. Overview of SPME experiments. SPME fiber types/coating volumes used for the different sorption experiments are indicated by the different background colors, as described in the legend below. The concentrations/cell numbers listed in this table indicate the concentration of biological material used for the experiments (BSA - bovine serum albumin, POPC - 1-palmitoyl-2-oleoyl-sn-glycero-3-phosphocholine, FBS - fetal bovine serum). The color code for the chosen SPME fibers is as follows:

$\begin{array}{lllll}\text { PDMS/198 } \mathrm{nL} & \mathrm{C} 18 / 520 \mathrm{~nL} & \mathrm{C} 18 / 173 \mathrm{~nL} \quad \mathrm{C} 18 / 69 \mathrm{~nL} \quad \text { not analyzed }\end{array}$

\begin{tabular}{|c|c|c|c|c|c|c|c|}
\hline Chemical & $\begin{array}{c}\text { fiber uptake } \\
\text { kinetics \& fiber- } \\
\text { water distribution }\end{array}$ & $\begin{array}{l}\text { fiber sorption } \\
\text { isotherm }\end{array}$ & $\begin{array}{l}\text { BSA-water } \\
\text { distribution }\end{array}$ & $\begin{array}{l}\text { liposome-water } \\
\text { distribution }\end{array}$ & $\begin{array}{l}\text { fiber-medium } \\
\text { distribution }\end{array}$ & $\begin{array}{l}\text { FBS sorption } \\
\text { isotherm }\end{array}$ & $\begin{array}{l}\text { cell-water } \\
\text { distribution }\end{array}$ \\
\hline \multicolumn{8}{|l|}{ Neutral chemicals } \\
\hline \multirow{6}{*}{$\begin{array}{l}\text { benzo[a]pyrene } \\
\text { benzo[k]fluoranthene } \\
\text { bisphenol A } \\
\text { quinoxyfen } \\
\text { triclocarban } \\
\text { fluoranthene }\end{array}$} & & & \multirow{3}{*}{$\begin{array}{l}1 \mathrm{~g} / \mathrm{L} \mathrm{BSA} \\
1 \mathrm{~g} / \mathrm{L} \mathrm{BSA}\end{array}$} & \multirow{6}{*}{$\begin{array}{c}1 \mathrm{~g} / \mathrm{L} \text { POPC } \\
0.1 \mathrm{~g} / \mathrm{L} \mathrm{POPC}\end{array}$} & & $1 \%$ FBS & $0.5 \times 10^{6}$ cells $/ \mathrm{mL}$ \\
\hline & & & & & & $1 \%$ FBS & $0.5 \times 10^{6} \mathrm{cell} / \mathrm{s} / \mathrm{mL}$ \\
\hline & & & & & & $10 \%$ FBS & $10-20 \times 10^{6} \mathrm{cells} / \mathrm{mL}$ \\
\hline & & & $1 \mathrm{~g} / \mathrm{L} \mathrm{BSA}$ & & & $1 \%$ FBS & $5 \times 10^{6} \mathrm{cells} / \mathrm{mL}$ \\
\hline & & & $1 \mathrm{~g} / \mathrm{L} \mathrm{BSA}$ & & & $0.5 \%$ FBS & $5 \times 10^{6} \mathrm{cells} / \mathrm{mL}$ \\
\hline & & & & & & $1 \%$ FBS & $3 \times 10^{6} \mathrm{cells} / \mathrm{mL}$ \\
\hline 6-gingerol & & & $10 \mathrm{~g} / \mathrm{L} \mathrm{BSA}$ & $10 \mathrm{~g} / \mathrm{L}$ POPC & & $10 \%$ FBS & $5-15 \times 10^{6}$ cells $/ \mathrm{mL}$ \\
\hline 8-gingerol & & & $10 \mathrm{~g} / \mathrm{L} \mathrm{BSA}$ & $5 \mathrm{~g} / \mathrm{L}$ POPC & & $90 \%$ FBS & $5 \times 10^{6} \mathrm{cells} / \mathrm{mL}$ \\
\hline caffeine & & & $50 \mathrm{~g} / \mathrm{L} \mathrm{BSA}$ & $49.5 \mathrm{~g} / \mathrm{L}$ POPC & & $90 \%$ FBS & \\
\hline coumarin & & & $10 \mathrm{~g} / \mathrm{L} \mathrm{BSA}$ & $5 \mathrm{~g} / \mathrm{L}$ POPC & & $90 \%$ FBS & $16-22 \times 10^{6} \mathrm{cell} / \mathrm{s} / \mathrm{mL}$ \\
\hline zingerone & & & $10 \mathrm{~g} / \mathrm{L} \mathrm{BSA}$ & $10 \mathrm{~g} / \mathrm{L}$ POPC & & $10 \%$ FBS & $11-22 \times 10^{6} \mathrm{cell} / \mathrm{s} / \mathrm{mL}$ \\
\hline lamotrigine & & & $5 \mathrm{~g} / \mathrm{L} \mathrm{BSA}$ & $5 \mathrm{~g} / \mathrm{L}$ POPC & & $90 \%$ FBS & $22 \times 10^{6} \mathrm{cells} / \mathrm{mL}$ \\
\hline \multicolumn{8}{|l|}{ lonizable chemicals } \\
\hline metoprolol & & & $50 \mathrm{~g} / \mathrm{L}$ BSA & $27-30 \mathrm{~g} / \mathrm{L}$ POPC & & $90 \%$ FBS & $15 \times 10^{6}$ cells $/ \mathrm{mL}$ \\
\hline propranolol & & & $50 \mathrm{~g} / \mathrm{L} \mathrm{BSA}$ & 10 g/L POPC & & $90 \%$ FBS & $13-22 \times 10^{6} \mathrm{cell} / \mathrm{s} / \mathrm{mL}$ \\
\hline diphenhydramine & & & $20 \mathrm{~g} / \mathrm{L} \mathrm{BSA}$ & 10 g/L POPC & & $90 \%$ FBS & \\
\hline venlafaxine & & & $50 \mathrm{~g} / \mathrm{L} \mathrm{BSA}$ & $10-27 \mathrm{~g} / \mathrm{L}$ POPC & & $90 \%$ FBS & \\
\hline diclofenac & & & $10 \mathrm{~g} / \mathrm{L} \mathrm{BSA}$ & $5-15 \mathrm{~g} / \mathrm{L}$ POPC & & $10 \%$ FBS & $8-22 \times 10^{6}$ cells $/ \mathrm{mL}$ \\
\hline $2,4-D$ & & & $10 \mathrm{~g} / \mathrm{L} \mathrm{BSA}$ & $10 \mathrm{~g} / \mathrm{L}$ POPC & & $10 \%$ FBS & $16-22 \times 10^{6} \mathrm{cell} / \mathrm{s} / \mathrm{mL}$ \\
\hline ibuprofen & & & $10 \mathrm{~g} / \mathrm{L} \mathrm{BSA}$ & $10-15 \mathrm{~g} / \mathrm{L}$ POPC & & $10 \%$ FBS & $8-22 \times 10^{6} \mathrm{cellls} / \mathrm{mL}$ \\
\hline naproxen & & & $10 \mathrm{~g} / \mathrm{L} \mathrm{BSA}$ & $10 \mathrm{~g} / \mathrm{L}$ POPC & & $10 \%$ FBS & $13-22 \times 10^{6} \mathrm{cell} / \mathrm{s} / \mathrm{mL}$ \\
\hline torasemide & & & $10 \mathrm{~g} / \mathrm{L} \mathrm{BSA}$ & $5-27 \mathrm{~g} / \mathrm{L}$ POPC & & $10 \%$ FBS & $13-22 \times 10^{6}$ cells $/ \mathrm{mL}$ \\
\hline warfarin & & & $10 \mathrm{~g} / \mathrm{L} \mathrm{BSA}$ & 15 g/L POPC & & $10 \%$ FBS & $16-22 \times 10^{6} \mathrm{cells} / \mathrm{mL}$ \\
\hline genistein & & & $10 \mathrm{~g} / \mathrm{L} \mathrm{BSA}$ & $5 \mathrm{~g} / \mathrm{L} P O P C$ & & $10 \%$ FBS & $16-22 \times 10^{6} \mathrm{celll} / \mathrm{mL}$ \\
\hline labetalol & & & $50 \mathrm{~g} / \mathrm{L} B S A$ & $10 \mathrm{~g} / \mathrm{L}$ POPC & & $90 \%$ FBS & $13-22 \times 10^{6} \mathrm{cell} / \mathrm{s} / \mathrm{mL}$ \\
\hline
\end{tabular}




\section{S2. Instrumental analysis}

\section{HPLC-UV/FLD}

- LC: Agilent HPLC 1260 Infinity

- DAD: 1260 Infinity Diode Array

- FLD: 1100/1200 Fluorescence detector

- column temperature set to $25-30{ }^{\circ} \mathrm{C}$

- flow rate: $0.8-1.2 \mathrm{~mL} / \mathrm{min}$

Table S3. HPLC-UV/FLD parameters.

\begin{tabular}{|c|c|c|c|c|c|c|}
\hline Chemical & Column & Eluent & Elution & Detector & Wavelength & $\begin{array}{l}\mathrm{LOQ} \\
{[\mathrm{mg} / \mathrm{L}]}\end{array}$ \\
\hline Benzo(a)pyrene & $\begin{array}{l}\text { Phenomenex Kinetex } 3.5 \mu \mathrm{m} \\
\text { PAH } 100 \AA, 100 \times 3.0 \mathrm{~mm}\end{array}$ & $\begin{array}{l}\text { A: water } \\
\text { B: acetonitrile }\end{array}$ & isocratic & FLD & $\begin{array}{l}\text { Ex } 260 \mathrm{~nm} \\
\text { Em } 405 \mathrm{~nm}\end{array}$ & 0.001 \\
\hline Benzo(k)fluoranthene & $\begin{array}{l}\text { Phenomenex Kinetex } 3.5 \mu \mathrm{m} \\
\text { PAH } 100 \AA, 100 \times 3.0 \mathrm{~mm}\end{array}$ & $\begin{array}{l}\text { A: water } \\
\text { B: acetonitrile }\end{array}$ & isocratic & FLD & $\begin{array}{l}\text { Ex } 260 \mathrm{~nm} \\
\text { Em } 455 \mathrm{~nm}\end{array}$ & 0.003 \\
\hline Bisphenol A & $\begin{array}{l}\text { Phenomenex Kinetex } 2.6 \mu \mathrm{m} \\
\mathrm{C} 18100 \AA, 50 \times 3.0 \mathrm{~mm}\end{array}$ & $\begin{array}{l}\text { A: water } \\
\text { B: acetonitrile }\end{array}$ & isocratic & FLD & $\begin{array}{l}\text { Ex } 230 \mathrm{~nm} \\
\text { Em } 310 \mathrm{~nm} \\
\end{array}$ & $\begin{array}{c}0.2\left(50 \% \mathrm{ACN} / 50 \% \mathrm{H}_{2} \mathrm{O}\right) \\
0.1(\mathrm{ACN})\end{array}$ \\
\hline Fluoranthene & $\begin{array}{l}\text { Phenomenex Kinetex } 5 \mu \mathrm{m} \\
\text { C18 100A 100x3.0 mm }\end{array}$ & $\begin{array}{l}\text { A: water } \\
\text { B: acetonitrile }\end{array}$ & gradient & FLD & $\begin{array}{l}\text { Ex } 260 \mathrm{~nm} \\
\text { Em } 455 \mathrm{~nm}\end{array}$ & $\begin{array}{c}0.005 \\
\left(50 \% \mathrm{ACN} / 50 \% \mathrm{H}_{2} \mathrm{O}\right) \\
0.01(\mathrm{ACN}) \\
\end{array}$ \\
\hline Quinoxyfen & $\begin{array}{l}\text { Phenomenex Kinetex } 2.6 \mu \mathrm{m} \\
\mathrm{C} 18100 \AA, 50 \times 3.0 \mathrm{~mm}\end{array}$ & $\begin{array}{l}\text { A: water } \\
\text { B: acetonitrile }\end{array}$ & gradient & DAD & $238 \mathrm{~nm}$ & $\begin{array}{c}0.004(\mathrm{PBS}) \\
0.1(\mathrm{ACN}) \\
\end{array}$ \\
\hline Triclocarban & $\begin{array}{l}\text { Phenomenex Kinetex } 2.6 \mu \mathrm{m} \\
\mathrm{C} 18100 \AA, 50 \times 3.0 \mathrm{~mm}\end{array}$ & $\begin{array}{l}\text { A: water } \\
\text { B: acetonitrile }\end{array}$ & gradient & DAD & $266 \mathrm{~nm}$ & $\begin{array}{l}0.002(\mathrm{PBS}) \\
0.08(\mathrm{ACN})\end{array}$ \\
\hline 6-Gingerol & $\begin{array}{l}\text { Phenomenex Kinetex } 2.6 \mu \mathrm{m} \\
\mathrm{C} 18100 \AA, 50 \times 3.0 \mathrm{~mm}\end{array}$ & $\begin{array}{l}\text { A: water } \\
\text { B: acetonitrile }\end{array}$ & gradient & DAD & $282 \mathrm{~nm}$ & 0.4 \\
\hline 8-Gingerol & $\begin{array}{l}\text { Phenomenex Kinetex } 2.6 \mu \mathrm{m} \\
\text { C18 } 100 \AA, 50 \times 3.0 \mathrm{~mm}\end{array}$ & $\begin{array}{l}\text { A: water } \\
\text { B: acetonitrile }\end{array}$ & gradient & DAD & $282 \mathrm{~nm}$ & 0.4 \\
\hline Caffeine & $\begin{array}{l}\text { Phenomenex Kinetex } 2.6 \mu \mathrm{m} \\
\text { Polar C18 100A 50x3.0 mm }\end{array}$ & $\begin{array}{l}\text { A: water } \\
\text { B: acetonitrile }\end{array}$ & gradient & DAD & $274 \mathrm{~nm}$ & 0.2 \\
\hline Coumarin & $\begin{array}{l}\text { Phenomenex Kinetex } 2.6 \mu \mathrm{m} \\
\mathrm{C} 18100 \AA, 50 \times 3.0 \mathrm{~mm}\end{array}$ & $\begin{array}{l}\text { A: water } \\
\text { B: acetonitrile }\end{array}$ & isocratic & DAD & $312 \mathrm{~nm}$ & 0.07 \\
\hline Zingerone & $\begin{array}{l}\text { Phenomenex Kinetex } 2.6 \mu \mathrm{m} \\
\mathrm{C} 18100 \AA, 50 \times 3.0 \mathrm{~mm}\end{array}$ & $\begin{array}{l}\text { A: water } \\
\text { B: acetonitrile }\end{array}$ & isocratic & DAD & $282 \mathrm{~nm}$ & 0.1 \\
\hline Lamotrigine & $\begin{array}{l}\text { Phenomenex Luna Omega } \\
\text { PS C18 100A } 50 \times 3.0 \mathrm{~mm}\end{array}$ & $\begin{array}{l}\text { A: water }+0.1 \% \mathrm{H}_{3} \mathrm{PO}_{4} \\
\text { B: acetonitrile }+0.1 \% \mathrm{H}_{3} \mathrm{PO}_{4}\end{array}$ & gradient & DAD & $270 \mathrm{~nm}$ & 0.1 \\
\hline
\end{tabular}


Table S3. continued

\begin{tabular}{|c|c|c|c|c|c|c|}
\hline Metoprolol & $\begin{array}{l}\text { Phenomenex Luna Omega } \\
\text { PS C18 100A 50x3.0 mm }\end{array}$ & $\begin{array}{l}\text { A: water }+0.1 \% \mathrm{H}_{3} \mathrm{PO}_{4} \\
\text { B: acetonitrile }+0.1 \% \mathrm{H}_{3} \mathrm{PO}_{4}\end{array}$ & gradient & DAD & $276 \mathrm{~nm}$ & 0.2 \\
\hline Propranolol & $\begin{array}{l}\text { Phenomenex Luna Omega } \\
\text { PS C18 100A 50x3.0 mm }\end{array}$ & $\begin{array}{l}\text { A: water }+0.1 \% \mathrm{H}_{3} \mathrm{PO}_{4} \\
\text { B: acetonitrile }+0.1 \% \mathrm{H}_{3} \mathrm{PO}_{4}\end{array}$ & gradient & DAD & $290 \mathrm{~nm}$ & 0.2 \\
\hline Diphenhydramine & $\begin{array}{l}\text { Phenomenex Luna Omega } \\
\text { PS C18 100A 50x3.0 mm }\end{array}$ & $\begin{array}{l}\mathrm{A}: \text { water }+0.1 \% \mathrm{H}_{3} \mathrm{PO}_{4} \\
\mathrm{~B}: \text { acetonitrile }+0.1 \% \mathrm{H}_{3} \mathrm{PO}_{4}\end{array}$ & gradient & DAD & $230 \mathrm{~nm}$ & 0.1 \\
\hline Venlafaxine & $\begin{array}{l}\text { Phenomenex Luna Omega } \\
\text { PS C18 100A 50x3.0 mm }\end{array}$ & $\begin{array}{l}\mathrm{A}: \text { water }+0.1 \% \mathrm{H}_{3} \mathrm{PO}_{4} \\
\mathrm{~B}: \text { acetonitrile }+0.1 \% \mathrm{H}_{3} \mathrm{PO}_{4}\end{array}$ & gradient & DAD & $276 \mathrm{~nm}$ & 0.2 \\
\hline Labetalol & $\begin{array}{l}\text { Phenomenex Kinetex } 2.6 \mu \mathrm{m} \\
\text { Polar C18 100A 50x3.0 mm }\end{array}$ & $\begin{array}{l}\mathrm{A}: \text { water }+0.1 \% \mathrm{H}_{3} \mathrm{PO}_{4} \\
\mathrm{~B}: \text { acetonitrile }+0.1 \% \mathrm{H}_{3} \mathrm{PO}_{4}\end{array}$ & isocratic & DAD & $304 \mathrm{~nm}$ & 0.05 \\
\hline
\end{tabular}

\section{LC-MS/MS}

- LC: Agilent HPLC 1260 Infinity II

- MS: 6420 Triple Quadrupole

- column temperature set to $25-40{ }^{\circ} \mathrm{C}$

- flow: $0.5 \mathrm{~mL} / \mathrm{min}$, isocratic

Table S4. LC-MS/MS parameters.

\begin{tabular}{|c|c|c|c|c|c|c|}
\hline Chemical & Column & Eluent & ESI & source conditions & $\begin{array}{l}\text { MS parameters } \\
\text { precursor }[\mathrm{m} / \mathrm{z}] \rightarrow \\
\text { product ions }[\mathrm{m} / \mathrm{z}]\end{array}$ & $\begin{array}{l}\mathrm{LOQ} \\
{[\mathrm{ng} / \mathrm{mL}]}\end{array}$ \\
\hline Quinoxyfen & $\begin{array}{l}\text { Phenomenex Kinetex C18 } 1.7 \mu \mathrm{m} \\
50 \times 21 . \mathrm{mm}\end{array}$ & $\begin{array}{l}\text { A: } 5 \% \text { ACN/ } 95 \% \text { water }+0.1 \% \text { FA } \\
\text { B: } 95 \% \text { ACN } 5 \% \text { water }+0.1 \% \text { FA }\end{array}$ & + & $\begin{array}{l}\text { gas temp. } 350^{\circ} \mathrm{C} \\
\text { gas flow } 13 \mathrm{~L} / \mathrm{min} \\
\text { nebulizer } 60 \mathrm{psi} \\
\text { capillary } 1500 \mathrm{~V}\end{array}$ & $308 \rightarrow 196.9 / 271.9$ & 1 \\
\hline Triclocarban & $\begin{array}{l}\text { Phenomenex Kinetex C18 } 1.7 \mu \mathrm{m} \\
50 \times 21 . \mathrm{mm}\end{array}$ & $\begin{array}{l}\text { A: } 5 \mathrm{mM} \mathrm{NH}{ }_{4} \mathrm{Ac} \text { in MilliQ (pH 5.5) } \\
\text { B: ACN }\end{array}$ & - & $\begin{array}{l}\text { gas temp. } 230^{\circ} \mathrm{C} \\
\text { gas flow } 13 \mathrm{~L} / \mathrm{min} \\
\text { nebulizer } 60 \mathrm{psi} \\
\text { capillary } 1500 \mathrm{~V}\end{array}$ & $312.97 \rightarrow 159.9$ & 5 \\
\hline $\begin{array}{l}\text { 6-Gingerol, } \\
\text { 8-Gingerol }\end{array}$ & $\begin{array}{l}\text { Phenomenex Kinetex C18 } 1.7 \mu \mathrm{m} \\
50 \times 21 . \mathrm{mm}\end{array}$ & $\begin{array}{l}\text { A: } 5 \% \text { ACN } / 95 \% \text { water }+0.1 \% \text { FA } \\
\text { B: } 95 \% \text { ACN } 5 \% \text { water }+0.1 \% \text { FA }\end{array}$ & + & $\begin{array}{l}\text { gas temp. } 320^{\circ} \mathrm{C} \\
\text { gas flow } 13 \mathrm{~L} / \mathrm{min} \\
\text { nebulizer } 40 \mathrm{psi} \\
\text { capillary } 5000 \mathrm{~V}\end{array}$ & $\begin{array}{l}277 \rightarrow 177 / 145 \\
305 \rightarrow 177 / 145\end{array}$ & 5 \\
\hline Caffeine & $\begin{array}{l}\text { Phenomenex Luna Omega Polar } \\
\text { C18 } 1.6 \mu \mathrm{m} 50 \times 21 . \mathrm{mm}\end{array}$ & $\begin{array}{l}\text { A: } 5 \% \text { ACN } / 95 \% \text { water } \\
\text { B: ACN }\end{array}$ & + & $\begin{array}{l}\text { gas temp. } 310^{\circ} \mathrm{C} \\
\text { gas flow } 13 \mathrm{~L} / \mathrm{min} \\
\text { nebulizer } 60 \mathrm{psi} \\
\text { capillary } 5000 \mathrm{~V}\end{array}$ & $195.2 \rightarrow 138 / 110.1$ & 5 \\
\hline
\end{tabular}


Table S4. continued.

\begin{tabular}{|c|c|c|c|c|c|c|}
\hline Coumarin & $\begin{array}{l}\text { Phenomenex Luna Omega Polar } \\
\text { C18 } 1.6 \mu \mathrm{m} 50 \times 21 . \mathrm{mm}\end{array}$ & $\begin{array}{l}\text { A: } 5 \% \text { ACN/ } 95 \% \text { water } \\
\text { B: ACN }\end{array}$ & + & $\begin{array}{l}\text { gas temp. } 280{ }^{\circ} \mathrm{C} \\
\text { gas flow } 10 \mathrm{~L} / \mathrm{min} \\
\text { nebulizer } 55 \mathrm{psi} \\
\text { capillary } 5000 \mathrm{~V}\end{array}$ & $147.16 \rightarrow 103 / 91$ & 5 \\
\hline Zingerone & $\begin{array}{l}\text { Phenomenex Luna Omega Polar } \\
\text { C18 } 1.6 \mu \mathrm{m} 50 \times 21 . \mathrm{mm}\end{array}$ & $\begin{array}{l}\text { A: } 5 \% \text { ACN/ } 95 \% \text { water } \\
\text { B: ACN }\end{array}$ & - & $\begin{array}{l}\text { gas temp. } 350{ }^{\circ} \mathrm{C} \\
\text { gas flow } 13 \mathrm{~L} / \mathrm{min} \\
\text { nebulizer } 60 \mathrm{psi} \\
\text { capillary } 5000 \mathrm{~V}\end{array}$ & $193.08 \rightarrow 51.7 / 177.9$ & 10 \\
\hline Lamotrigine & $\begin{array}{l}\text { Phenomenex BioZen peptide PS- } \\
\text { C18 } 1.6 \mu \mathrm{m} 50 \times 2.1 \mathrm{~mm}\end{array}$ & $\begin{array}{l}\text { A: } 5 \% \text { ACN/ } 95 \% \text { water }+0.1 \% \text { FA } \\
\text { B: } 95 \% \text { ACN/ } 5 \% \text { water }+0.1 \% \text { FA }\end{array}$ & + & $\begin{array}{l}\text { gas temp. } 290{ }^{\circ} \mathrm{C} \\
\text { gas flow } 13 \mathrm{~L} / \mathrm{min} \\
\text { nebulizer } 50 \mathrm{psi} \\
\text { capillary } 3000 \mathrm{~V}\end{array}$ & $256 \rightarrow 211 / 145$ & 5 \\
\hline Metoprolol & $\begin{array}{l}\text { Phenomenex BioZen peptide PS- } \\
\text { C18 } 1.6 \mu \mathrm{m} 50 \times 2.1 \mathrm{~mm}\end{array}$ & $\begin{array}{l}\text { A: } 5 \% \text { ACN/ } 95 \% \text { water }+0.1 \% \text { FA } \\
\text { B: } 95 \% \text { ACN/ } 5 \% \text { water }+0.1 \% \text { FA }\end{array}$ & + & $\begin{array}{l}\text { gas temp. } 350{ }^{\circ} \mathrm{C} \\
\text { gas flow } 13 \mathrm{~L} / \mathrm{min} \\
\text { nebulizer } 60 \mathrm{psi} \\
\text { capillary } 2500 \mathrm{~V}\end{array}$ & $268 \rightarrow 116 / 121$ & 5 \\
\hline Propranolol & $\begin{array}{l}\text { Phenomenex BioZen peptide PS- } \\
\text { C18 } 1.6 \mu \mathrm{m} 50 \times 2.1 \mathrm{~mm}\end{array}$ & $\begin{array}{l}\text { A: } 5 \% \text { ACN/ } 95 \% \text { water }+0.1 \% \text { FA } \\
\text { B: } 95 \% \text { ACN/ } 5 \% \text { water }+0.1 \% \text { FA }\end{array}$ & + & $\begin{array}{l}\text { gas temp. } 350{ }^{\circ} \mathrm{C} \\
\text { gas flow } 13 \mathrm{~L} / \mathrm{min} \\
\text { nebulizer } 60 \mathrm{psi} \\
\text { capillary } 2000 \mathrm{~V}\end{array}$ & $260 \rightarrow 116 / 183$ & 10 \\
\hline $\begin{array}{l}\text { Diphen- } \\
\text { hydramine }\end{array}$ & $\begin{array}{l}\text { Phenomenex BioZen peptide PS- } \\
\text { C18 } 1.6 \mu \mathrm{m} 50 \times 2.1 \mathrm{~mm}\end{array}$ & $\begin{array}{l}\text { A: } 5 \% \text { ACN/ } 95 \% \text { water }+0.1 \% \text { FA } \\
\text { B: } 95 \% \text { ACN/ } 5 \% \text { water }+0.1 \% \text { FA }\end{array}$ & + & $\begin{array}{l}\text { gas temp. } 350{ }^{\circ} \mathrm{C} \\
\text { gas flow } 13 \mathrm{~L} / \mathrm{min} \\
\text { nebulizer } 60 \mathrm{psi} \\
\text { capillary } 1500 \mathrm{~V}\end{array}$ & $256 \rightarrow 167 / 152$ & 5 \\
\hline Venlafaxine & $\begin{array}{l}\text { Phenomenex BioZen peptide PS- } \\
\text { C18 } 1.6 \mu \mathrm{m} 50 \times 2.1 \mathrm{~mm}\end{array}$ & $\begin{array}{l}\text { A: } 5 \% \text { ACN/ } 95 \% \text { water }+0.1 \% \text { FA } \\
\text { B: } 95 \% \text { ACN/ } 5 \% \text { water }+0.1 \% \text { FA }\end{array}$ & + & $\begin{array}{l}\text { gas temp. } 350{ }^{\circ} \mathrm{C} \\
\text { gas flow } 13 \mathrm{~L} / \mathrm{min} \\
\text { nebulizer } 60 \mathrm{psi} \\
\text { capillary } 2000 \mathrm{~V}\end{array}$ & $278 \rightarrow 260 / 121$ & 5 \\
\hline Labetalol & $\begin{array}{l}\text { Phenomenex Kinetex C18 } 1.7 \mu \mathrm{m} \\
50 \times 21 . \mathrm{mm}\end{array}$ & $\begin{array}{l}\text { A: } 5 \% \text { ACN/ } 95 \% \text { water }+0.1 \% \text { FA } \\
\text { B: } 95 \% \text { ACN/ } 5 \% \text { water }+0.1 \% \text { FA }\end{array}$ & + & $\begin{array}{l}\text { gas temp. } 350{ }^{\circ} \mathrm{C} \\
\text { gas flow } 13 \mathrm{~L} / \mathrm{min} \\
\text { nebulizer } 40 \mathrm{psi} \\
\text { capillary } 2000 \mathrm{~V}\end{array}$ & $329.19 \rightarrow 311 / 91$ & 5 \\
\hline
\end{tabular}




\section{S3. Kinetics of fiber uptake}

Figure S1. Fiber uptake kinetics of the test chemicals. The dotted grey vertical line indicates

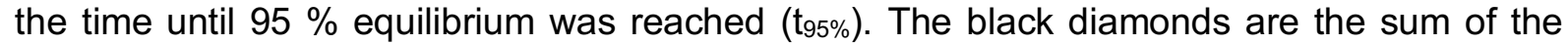
amount of the chemical in the fiber $\left(n_{\mathrm{f}}\right)$ and in water $\left(n_{\mathrm{w}}\right)$ and can be compared with the dashed black horizontal line, which is the total amount of chemical added to the vial.

A) Triclocarban

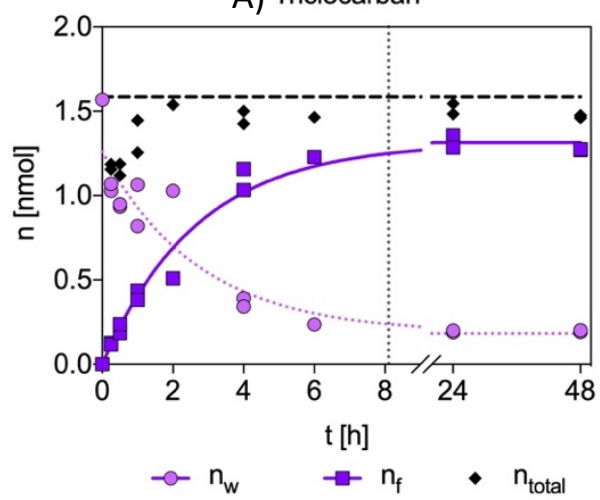

C) 6-Gingerol

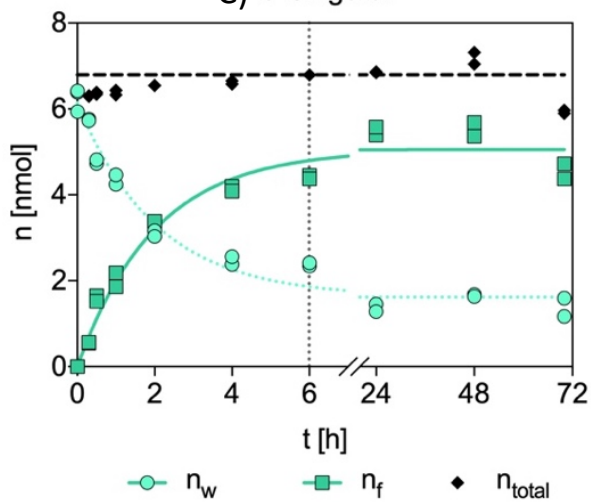

E) Zingerone

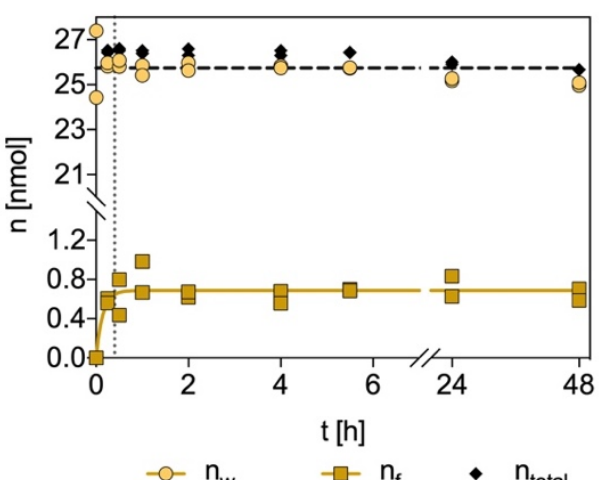

G) Diphenhydramine

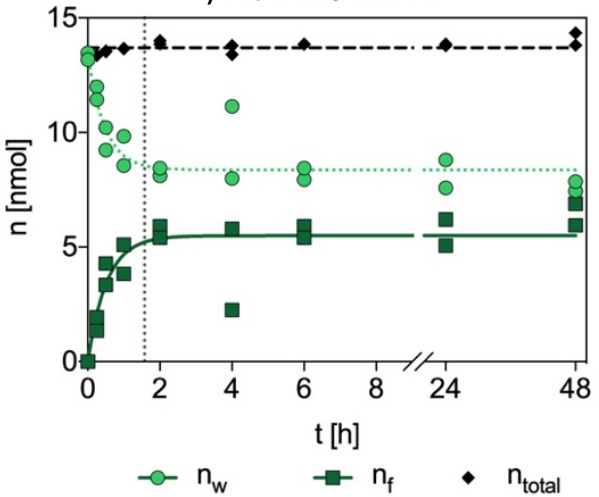

B) Fluoranthene

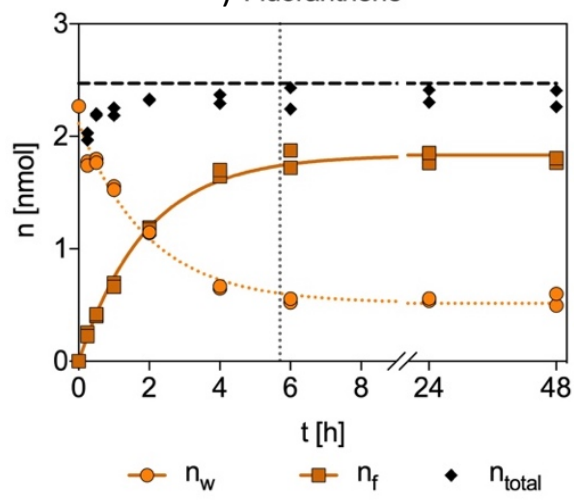

D) 8-Gingerol

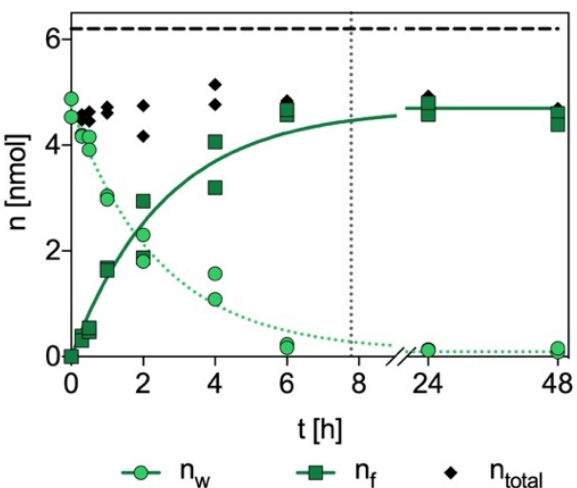

F) Lamotrigine

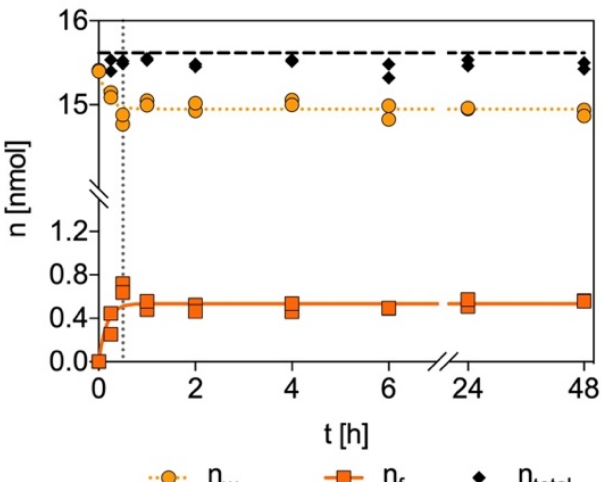

H) Venlafaxine

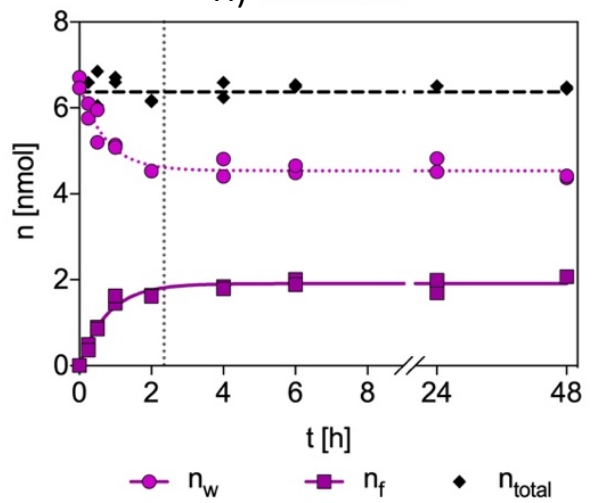




\section{S4. Comparison of equilibration times and fiber-water distribution ratios}

Figure S2. Correlation of equilibration times (t95\%) with fiber-water distribution ratios $\left(D_{f / w}\right)$.

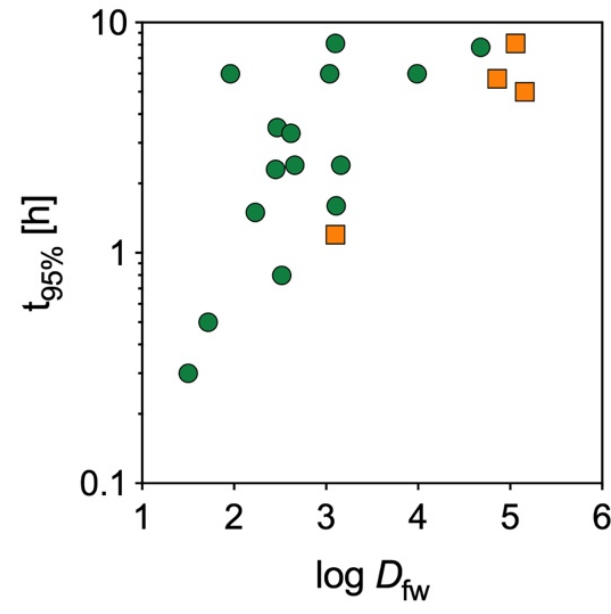

- $250 \mathrm{rpm}$

- $1200 \mathrm{rpm}$

S5. Comparison of fiber-water, BSA-water, liposome-water, FBSwater and cell-water distribution ratios with octanol-water partition constants

Figure S3. Correlation of fiber-water $\left(D_{\mathrm{f} / \mathrm{w}}\right)$, BSA-water $\left(D_{\mathrm{BSA} / \mathrm{w}}\right)$, liposome-water $\left(D_{\mathrm{lip} / \mathrm{w}}\right)$, FBSwater $\left(D_{\mathrm{FBS} / \mathrm{w}}\right)$ and cell-water distribution ratios $\left(D_{\text {cell/w) }}\right)$ with octanol-water partition constant $\left(K_{\text {ow }}\right)$ of neutral chemicals.
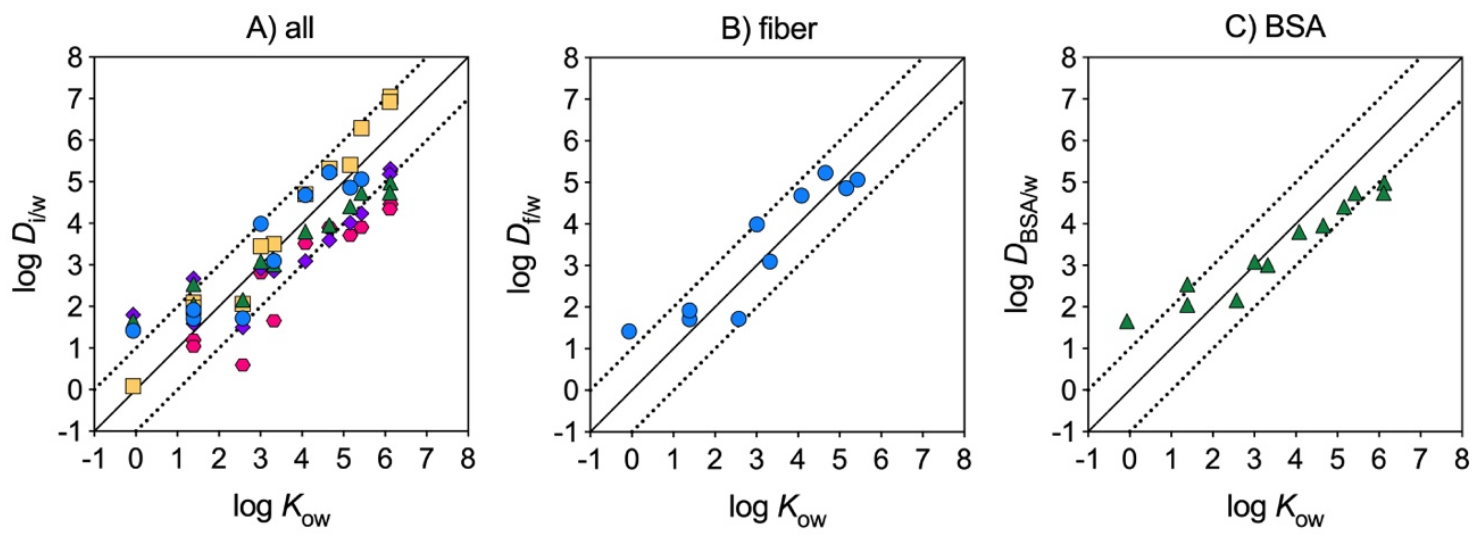

- $\log D_{\mathrm{f} / \mathrm{w}} \Delta \log D_{\mathrm{BSA} / \mathrm{w}} \square \log D_{\mathrm{lip} / \mathrm{w}} \bullet \log D_{\mathrm{FBS} / \mathrm{w}} \bullet \log D_{\mathrm{cell} / \mathrm{w}}$
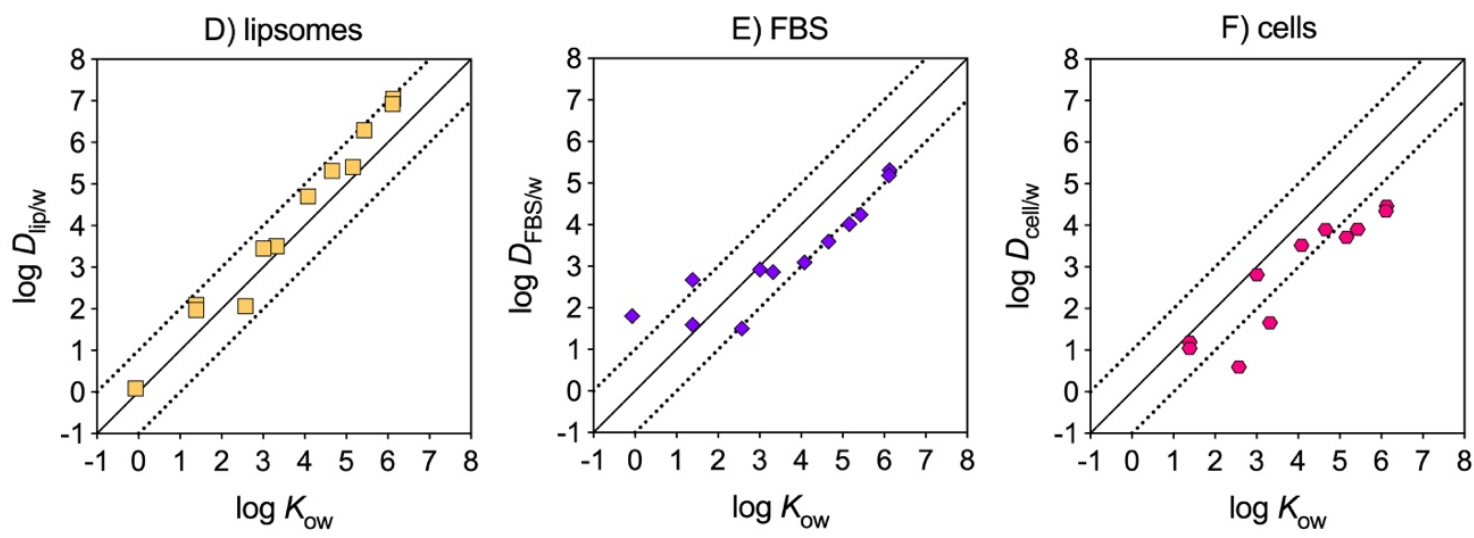


\section{S6. Fiber sorption isotherms}

Figure S4. Fiber sorption isotherms of all test chemicals. The solid lines indicate the fitted Freundlich isotherms, the dotted lines show the fit with a fixed slope of 1.

A) 6-Gingerol

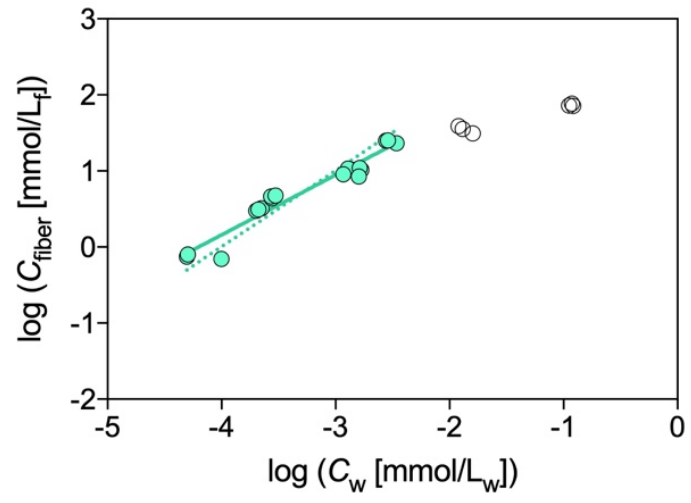

C) Caffeine

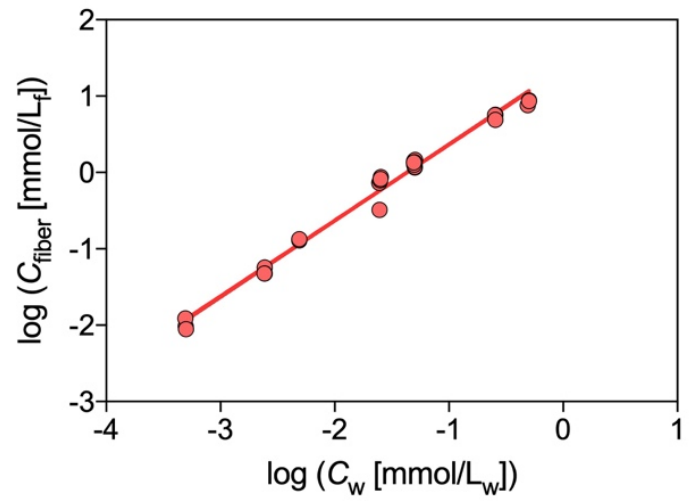

E) Zingerone

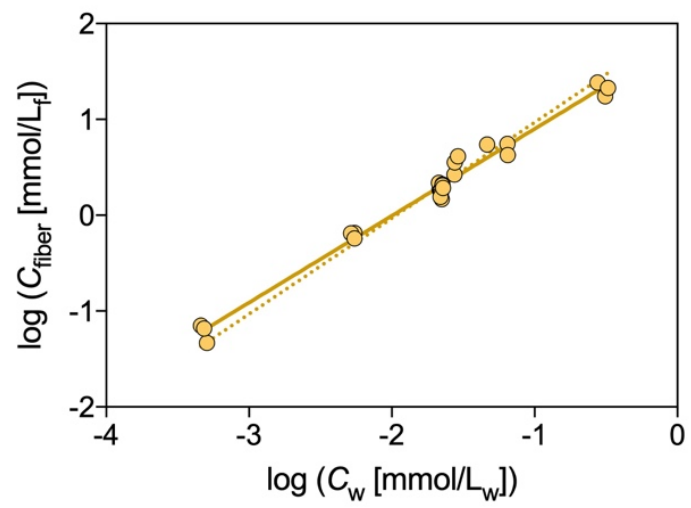

G) Metoprolol

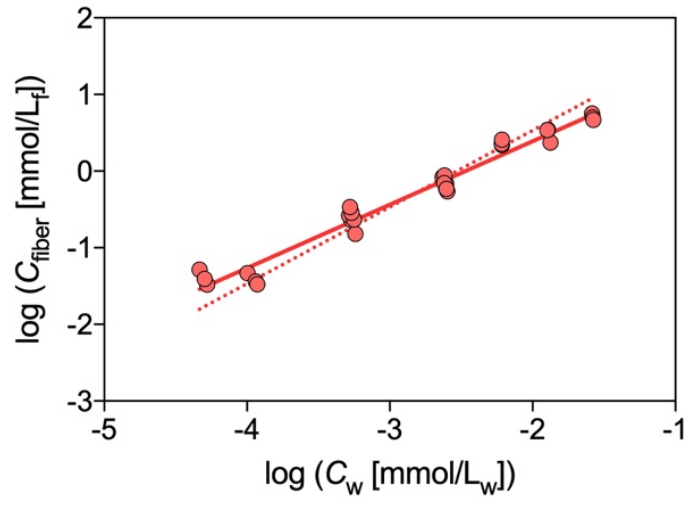

B) 8-Gingerol
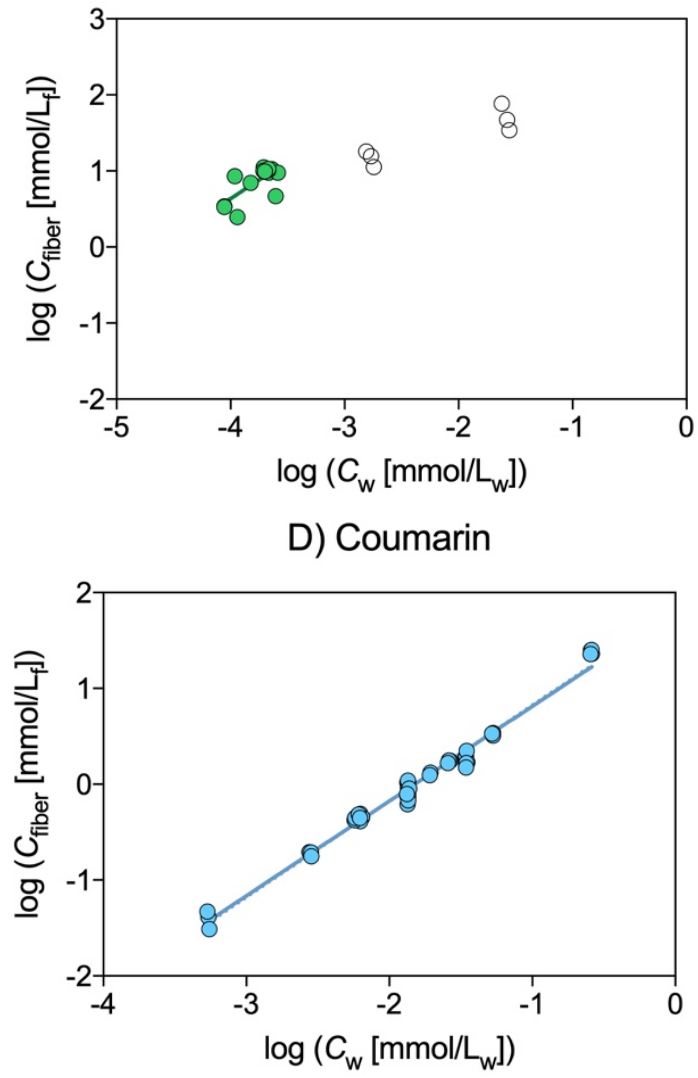

F) Lamotrigine

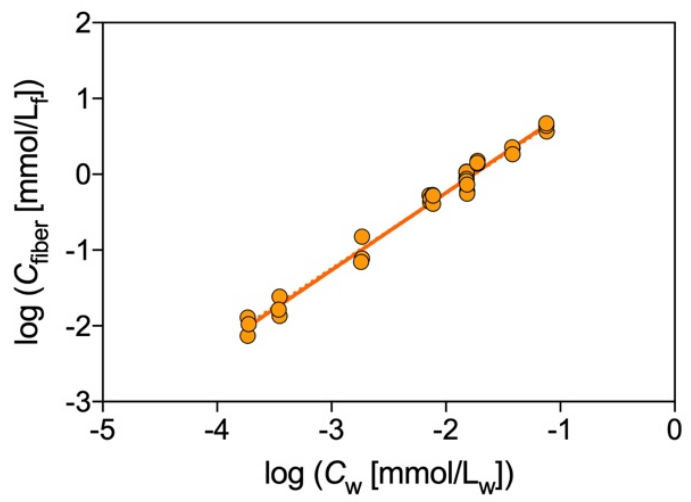

H) Propranolol

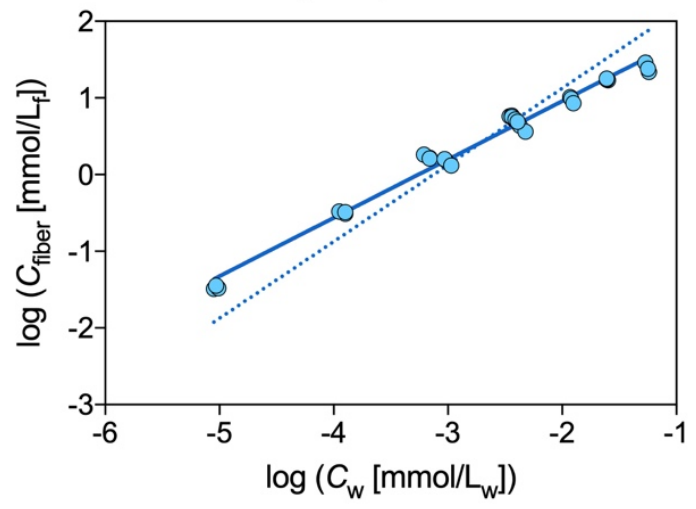


I) Diphenhydramine

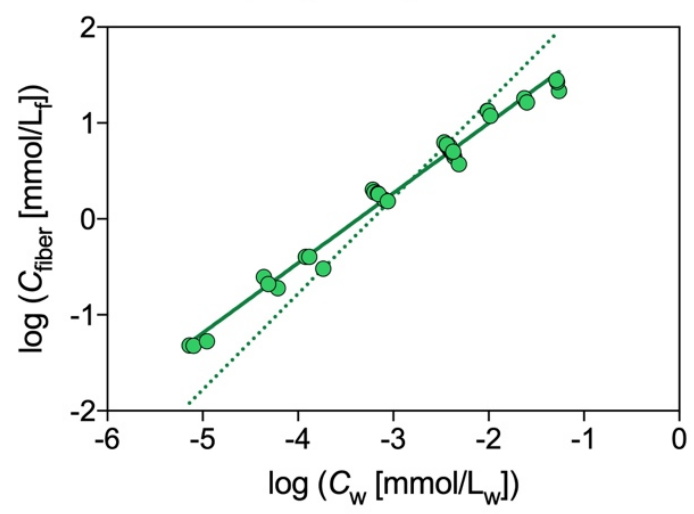

K) Labetalol

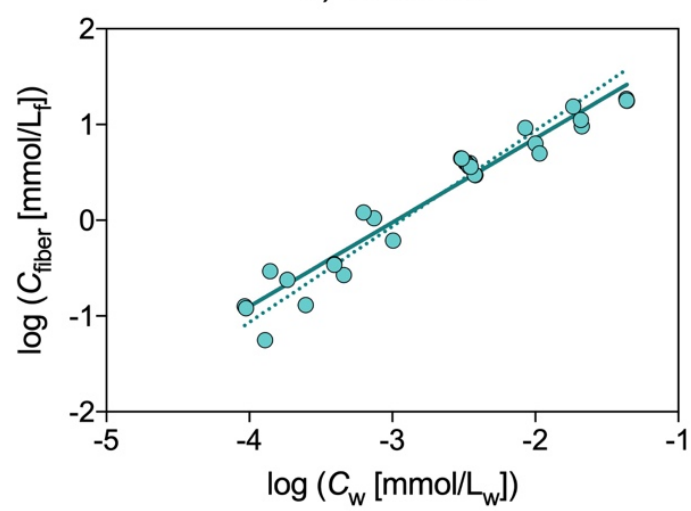

J) Venlafaxine

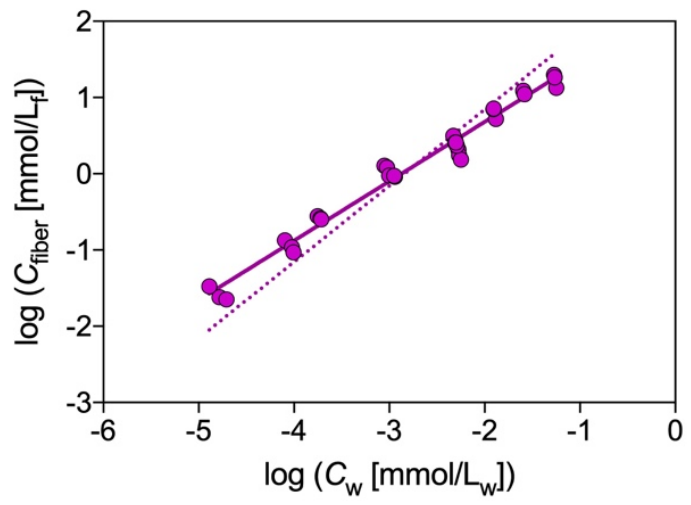

\section{S7. Comparison of BSA-water and liposome-water distribution ratios}

Figure S5. Comparison of BSA-water ( $\left.D_{\mathrm{BSA} / \mathrm{w}}\right)$ and liposome-water distribution ratios $\left(D_{\text {lip/w }}\right)$ of the chemicals.

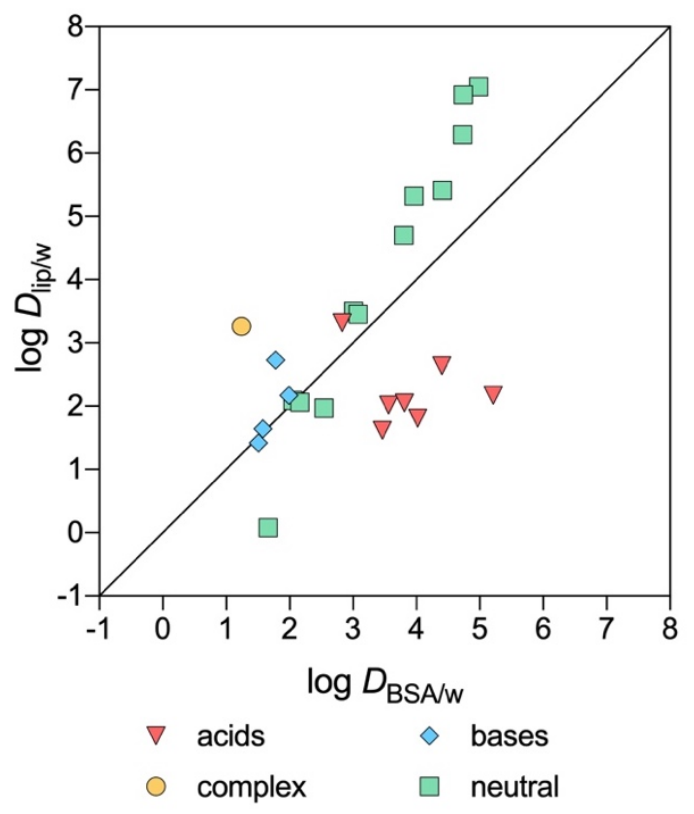

For the neutral test chemicals $D_{\mathrm{BSA} / \mathrm{w}}$ correlated with

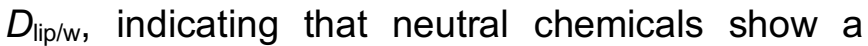
rather non-specific binding (i.e., partitioning) to BSA, which is in line with the findings of previous studies $[12,13]$. Both, $D_{\mathrm{BSA} / \mathrm{w}}$ and $D_{\text {lip/w }}$ also correlated with log $K_{\text {ow }}$ (Fig. S $3 \mathrm{C}+\mathrm{D}$ ). For the ionizable chemicals there was no correlation between $D_{\mathrm{BSA} / \mathrm{w}}$ and $D_{\mathrm{lip} / \mathrm{w}}$. All organic acids (except genistein) showed strong binding to serum albumin, independent of hydrophobicity, because the protein offers attractive binding sites for negatively charged chemicals, but much weaker binding to liposomes up to a factor of 1000 (for naproxen). For the organic bases $D_{\mathrm{BSA} / \mathrm{w}}$ and $D_{\text {lip/w }}$ were very similar, while for the chemical labetalol (47\% cationic and $53 \%$ zwitterionic at $\mathrm{pH} 7.4) D_{\text {lip/w }}$ was higher than $D_{\mathrm{BSA} / \mathrm{w}}$ by a factor of 100 . 


\section{S8. FBS sorption isotherms}

Figure S6. FBS sorption isotherms of the test chemicals, the dotted line indicates the linear sorption isotherm predicted by the mass balance model.

A) Bisphenol A

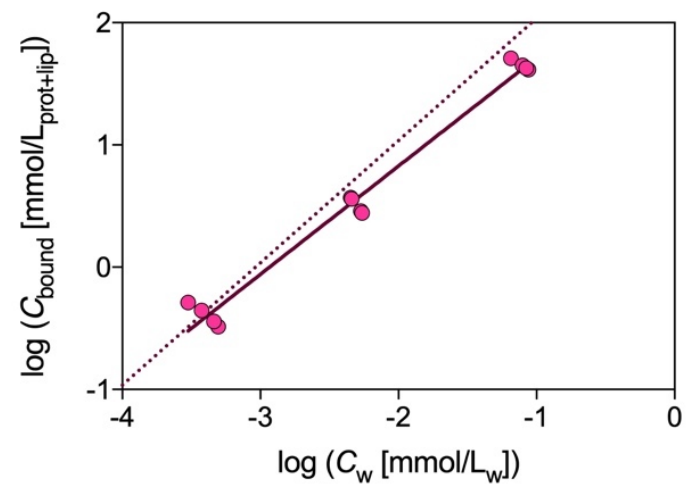

C) Triclocarban

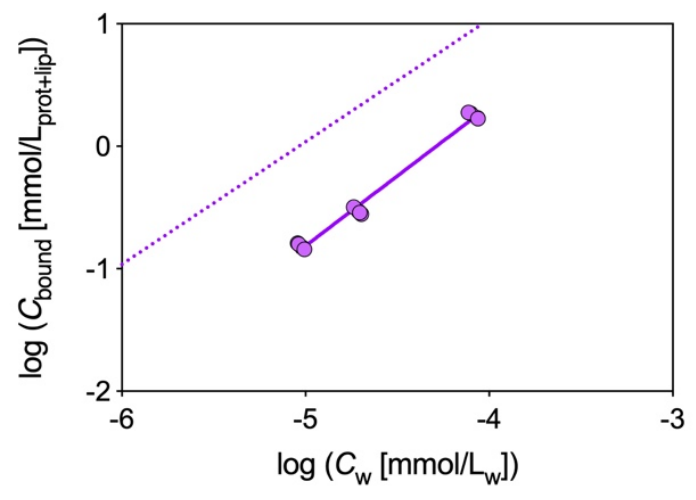

E) 6-Gingerol

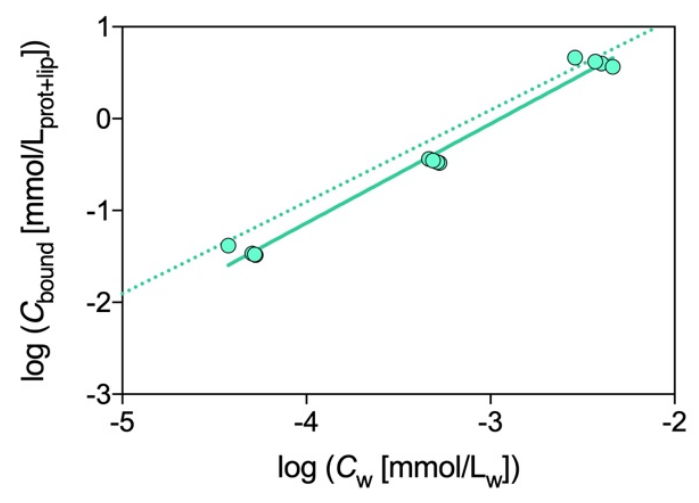

G) Caffeine

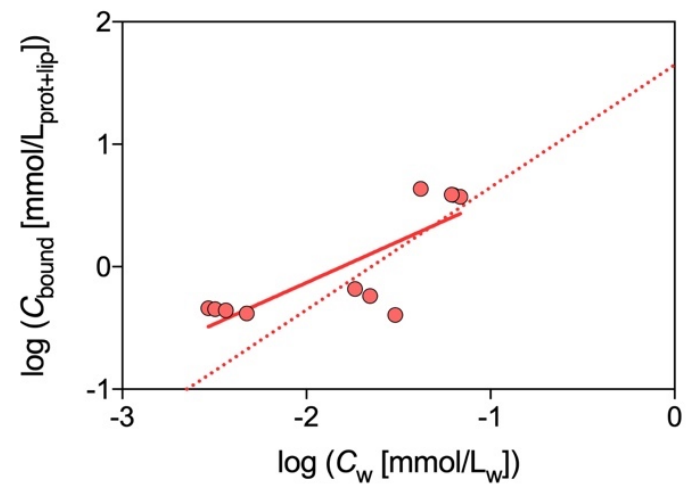

B) Quinoxyfen

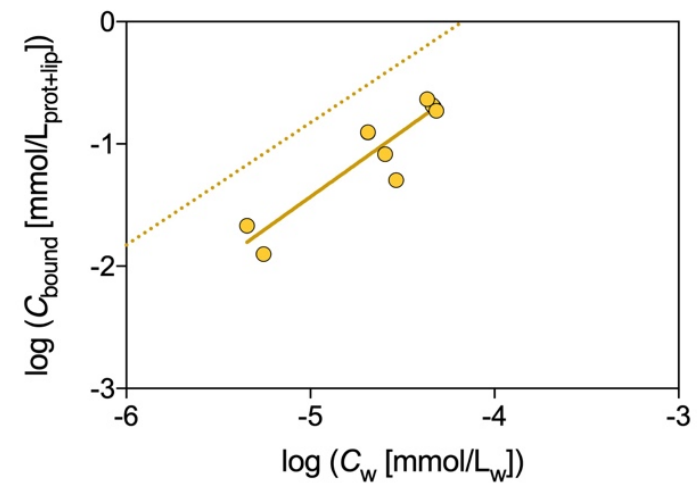

D) Fluoranthene

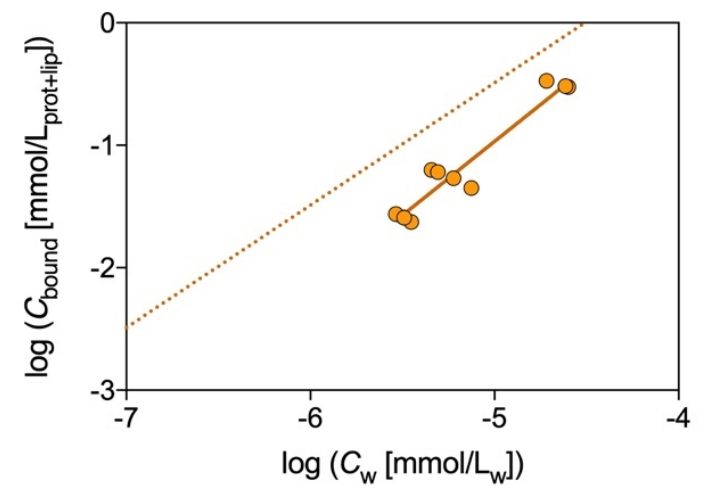

F) 8-Gingerol

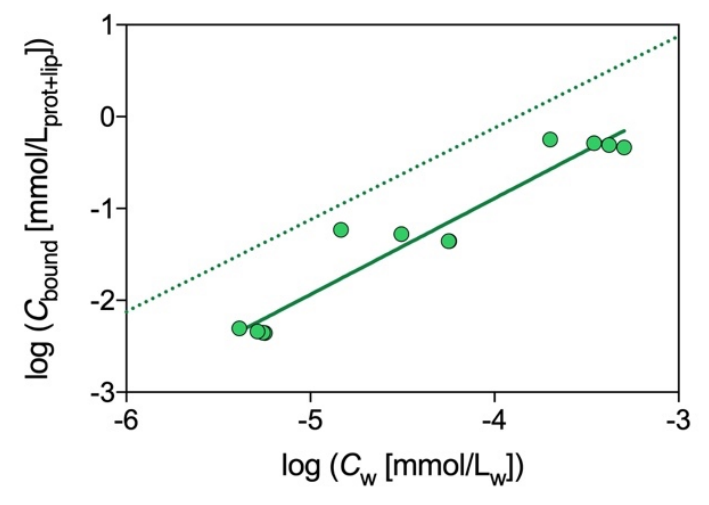

H) Coumarin

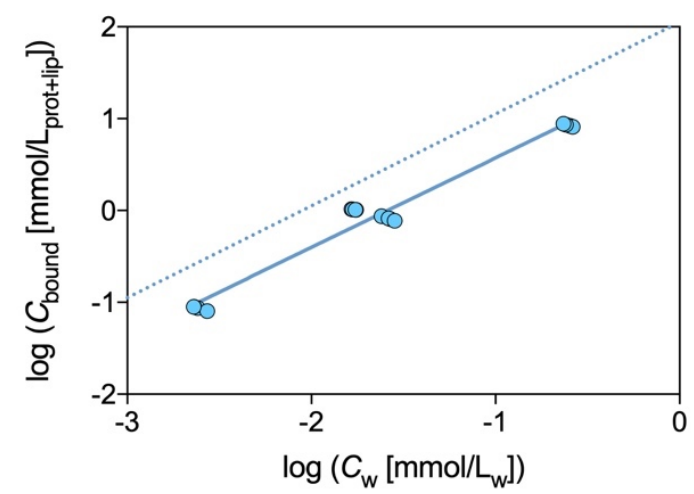


I) Zingerone

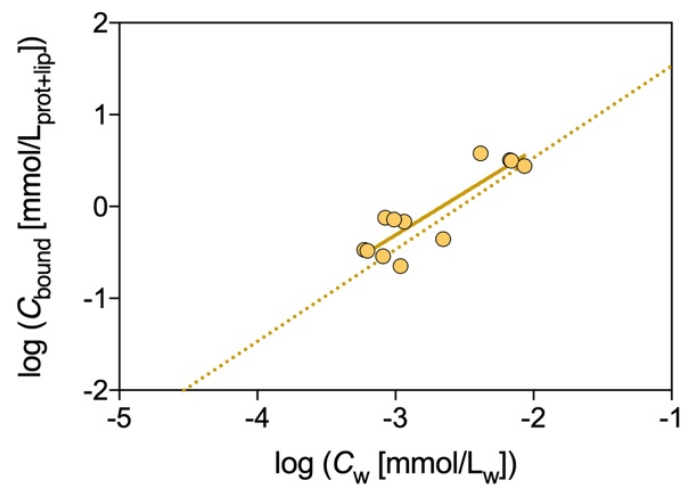

K) Metoprolol

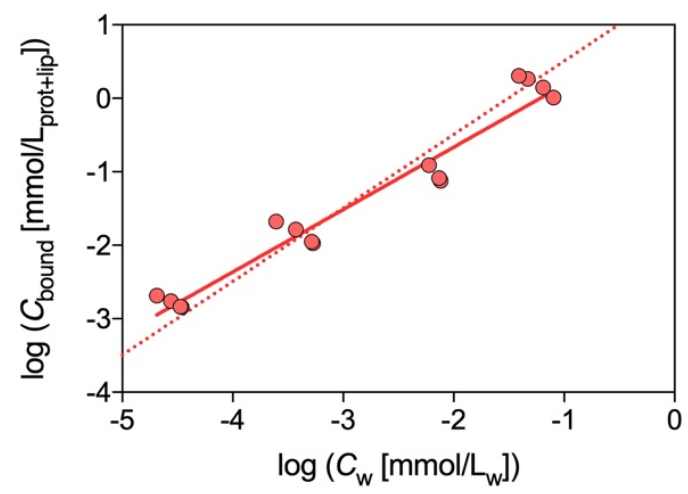

M) Diphenhydramine
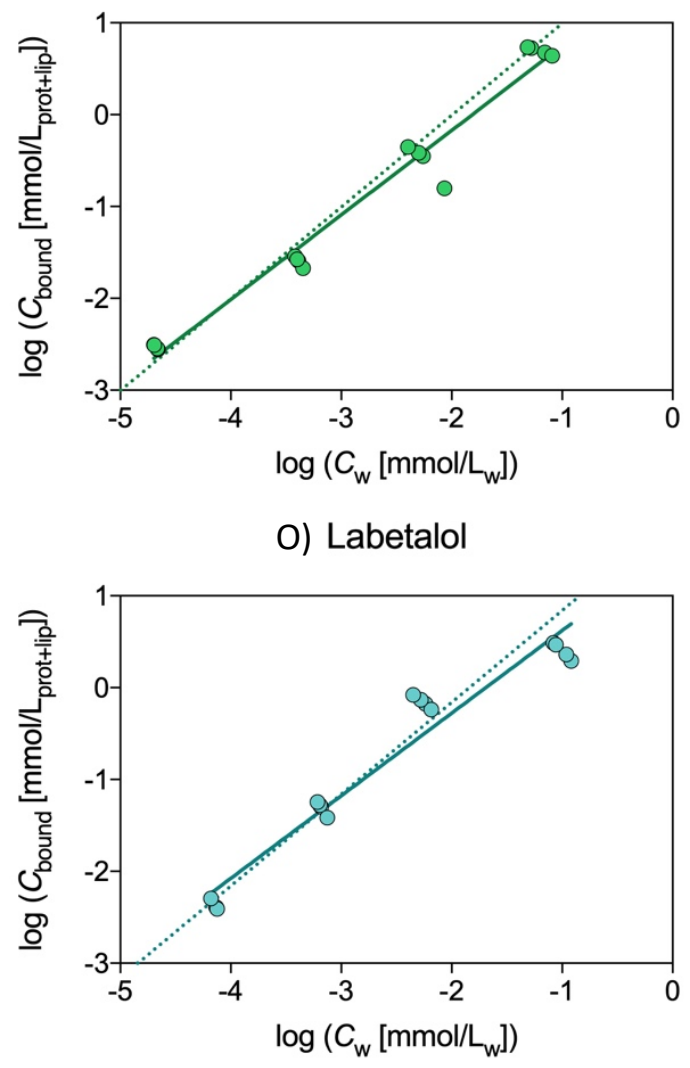

J) Lamotrigine

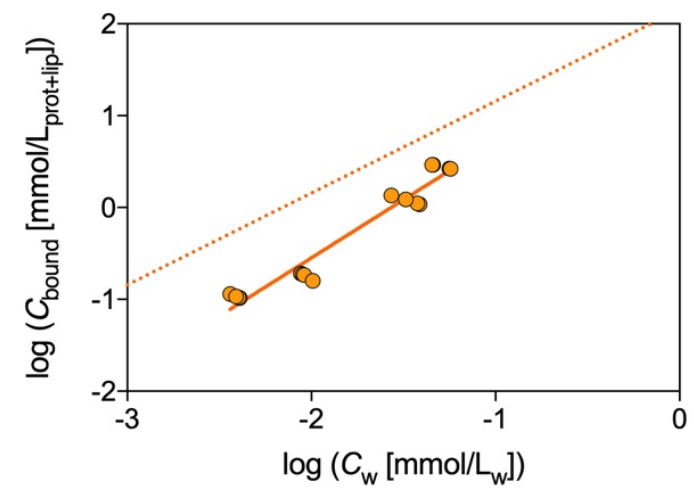

L) Propranolol

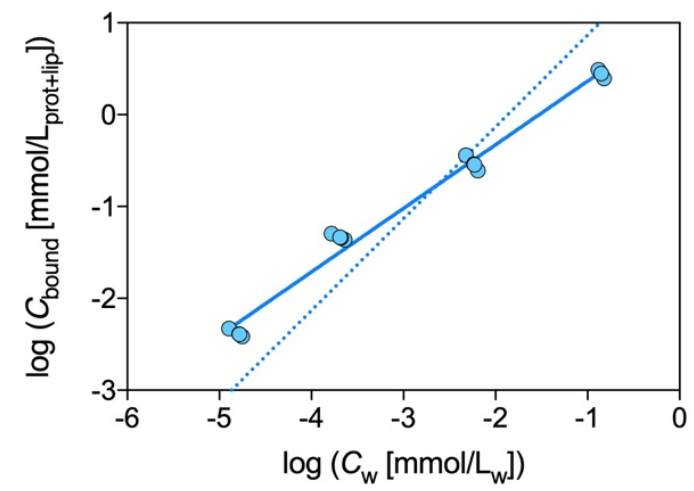

N) Venlafaxine

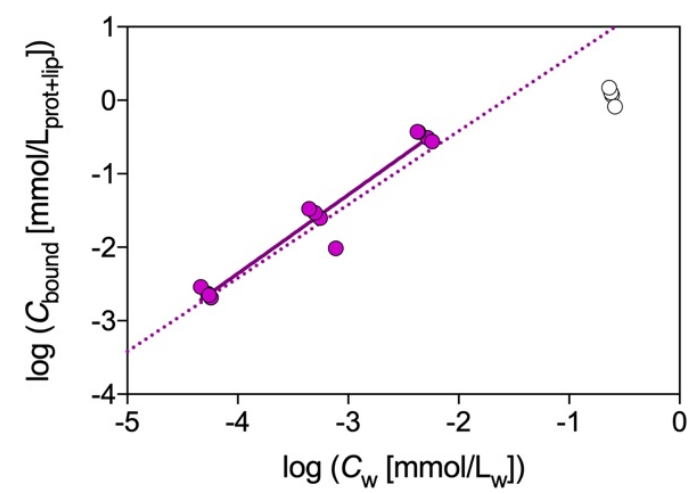




\section{S9. Estimation of protein saturation}

Table S5. Experimental (PhysProp) or predicted (OPERA) aqueous solubilities $\left(S_{w}\right)$ of the neutral chemicals from the CompTox Chemistry Dashboard [14] and estimated ratios chemical:BSA at $C_{\text {free }}=S_{w}(v)$.

\begin{tabular}{lccc}
\hline Chemical & $\mathbf{S}_{\mathbf{w}}[\mathbf{m o l} / \mathrm{L}]$ & Reference & $\mathbf{v}$ [mol $_{\text {chemical }} / \mathbf{m o l}_{\text {BSA }}$ \\
\hline Neutral chemicals & & & \\
\hline benzo[a]pyrene & $6.42 \mathrm{E}-09$ & PhysProp & 0.03 \\
benzo[k]fluoranthene & $3.17 \mathrm{E}-09$ & PhysProp & 0.01 \\
bisphenol A & $5.26 \mathrm{E}-04$ & PhysProp & 26.30 \\
quinoxyfen & $3.76 \mathrm{E}-07$ & PhysProp & 0.17 \\
triclocarban & $1.03 \mathrm{E}-04$ & OPERA & 270.32 \\
fluoranthene & $1.14 \mathrm{E}-06$ & PhysProp & 1.43 \\
6-gingerol & $1.13 \mathrm{E}-02$ & OPERA & 663.93 \\
8-gingerol & $1.13 \mathrm{E}-03$ & OPERA & 348.43 \\
caffeine & $1.08 \mathrm{E}-01$ & PhysProp & 241.25 \\
coumarin & $1.30 \mathrm{E}-02$ & PhysProp & 71.28 \\
zingerone & $1.66 \mathrm{E}-02$ & OPERA & 281.29 \\
lamotrigine & $3.24 \mathrm{E}-04$ & OPERA & 2.29 \\
\hline
\end{tabular}




\section{S10. Cell-water distribution ratios and ANOVA test}

Table S6. Determined distribution ratios between cells and water $\left(D_{\text {cell/w }}\right)$ at $\mathrm{pH} 7.4$ and $37^{\circ} \mathrm{C}$ for four different cell lines.

\begin{tabular}{|c|c|c|c|c|c|c|c|c|c|c|c|c|}
\hline \multirow{2}{*}{ Chemical } & \multicolumn{3}{|c|}{ HEK293T } & \multicolumn{3}{|c|}{ HEK293H } & \multicolumn{3}{|c|}{ MCF7 } & \multicolumn{3}{|c|}{ H4lle } \\
\hline & $\begin{array}{c}\log D_{\text {cell } / \mathrm{w}} \\
{\left[\mathrm{L}_{\text {water }} / \mathrm{L}_{\text {cell }}\right]} \\
\mathrm{pH} 7.4,37^{\circ} \mathrm{C}\end{array}$ & SD & $\mathbf{n}$ & $\begin{array}{c}\log D_{\text {cell } / \text { w }} \\
{\left[L_{\text {water }} / L_{\text {cell }}\right]} \\
\text { pH } 7.4,37^{\circ} \mathrm{C}\end{array}$ & SD & $\mathbf{n}$ & $\begin{array}{c}\log D_{\text {cell } / \mathrm{w}} \\
{\left[\mathrm{L}_{\text {water }} / L_{\text {cell }}\right]} \\
\mathrm{pH} 7.4,37^{\circ} \mathrm{C}\end{array}$ & SD & $\mathbf{n}$ & $\begin{array}{c}\log D_{\text {cell/w }} \\
{\left[L_{\text {water }} / L_{\text {cell }}\right]} \\
\text { pH 7.4, } 37^{\circ} \mathrm{C}\end{array}$ & SD & $\mathbf{n}$ \\
\hline $\mathrm{B}[\mathrm{a}] \mathrm{P}$ & 4.34 & 0.11 & 6 & n.a. & - & - & n.a. & - & - & 4.57 & 0.09 & 6 \\
\hline $\mathrm{B}[\mathrm{k}] \mathrm{F}$ & 4.22 & 0.10 & 6 & n.a. & - & - & n.a. & - & - & 4.47 & 0.08 & 6 \\
\hline bisphenol A & 1.34 & 0.13 & 6 & 2.03 & 0.35 & 9 & 1.45 & 0.05 & 3 & 1.56 & 0.10 & 6 \\
\hline quinoxyfen & n.a. & - & - & 4.09 & 0.21 & 3 & 3.80 & 0.19 & 3 & 3.87 & 0.39 & 9 \\
\hline triclocarban & n.a. & - & - & 4.02 & 0.16 & 6 & 3.60 & 0.11 & 6 & 4.05 & 0.20 & 9 \\
\hline fluoranthene & 3.60 & 0.10 & 3 & 3.81 & 0.05 & 3 & 3.31 & 0.11 & 3 & 4.11 & 0.13 & 3 \\
\hline 6-gingerol & 2.42 & 0.21 & 3 & 2.62 & 0.08 & 3 & 3.53 & 0.51 & 3 & 2.66 & 0.65 & 3 \\
\hline 8-gingerol & 3.52 & 0.21 & 3 & 3.40 & 0.02 & 3 & 3.15 & 0.17 & 3 & 3.99 & 0.24 & 3 \\
\hline caffeine & n.a. & - & - & n.a. & - & - & n.a. & - & - & n.a. & - & - \\
\hline coumarin & 1.80 & 0.12 & 3 & 0.93 & 0.11 & 3 & 0.48 & 0.07 & 3 & 1.57 & 0.15 & 3 \\
\hline zingerone & 0.67 & 0.12 & 3 & 1.44 & 0.21 & 3 & 1.00 & 0.30 & 3 & 1.03 & 0.53 & 3 \\
\hline lamotrigine & 0.59 & 0.06 & 3 & n.a. & - & - & $<0.28$ & - & - & $<0.18$ & - & - \\
\hline metoprolol & $<0.42$ & - & - & n.a. & - & - & 0.80 & 0.18 & 3 & n.a. & - & - \\
\hline propranolol & 0.64 & 0.36 & 3 & $<1.22$ & & & 0.96 & 0.12 & 3 & $<0.75$ & - & - \\
\hline diphenhydramine & n.a. & - & - & n.a. & - & - & n.a. & - & - & n.a. & - & - \\
\hline venlafaxine & n.a. & - & - & n.a. & - & - & n.a. & - & - & n.a. & - & - \\
\hline diclofenac* & $1.19^{*}$ & $0.09^{*}$ & $2^{*}$ & $1.62^{*}$ & $0.05^{*}$ & $3^{*}$ & $1.47^{*}$ & $0.02^{*}$ & $3^{*}$ & $1.47^{*}$ & $0.42^{*}$ & $3^{*}$ \\
\hline $2,4-D^{*}$ & $0.97^{*}$ & $0.21^{*}$ & $3^{*}$ & $1.19^{*}$ & $0.14^{*}$ & $3^{*}$ & $0.99^{*}$ & $0.03^{*}$ & $3^{*}$ & $1.45^{\star}$ & $0.24^{*}$ & $3^{*}$ \\
\hline ibuprofen* & $1.45^{*}$ & $0.09^{*}$ & $3^{*}$ & $1.46^{*}$ & $0.11^{*}$ & $3^{*}$ & $0.77^{*}$ & $0.24^{*}$ & $3^{*}$ & $1.54^{*}$ & $0.47^{*}$ & $3^{*}$ \\
\hline naproxen* & $0.87^{*}$ & $0.20^{*}$ & $3^{*}$ & $2.20^{*}$ & $0.12^{*}$ & $3^{*}$ & $1.25^{*}$ & $0.13^{*}$ & $3^{*}$ & $1.88^{*}$ & $0.24^{*}$ & $3^{*}$ \\
\hline torasemide ${ }^{*}$ & $1.51^{*}$ & $0.27^{*}$ & $6^{*}$ & $2.70^{*}$ & $0.05^{*}$ & $3^{*}$ & $0.87^{*}$ & $0.48^{*}$ & $3^{*}$ & $1.76^{*}$ & $0.22^{*}$ & $3^{*}$ \\
\hline warfarin* & $0.83^{*}$ & $0.14^{*}$ & $3^{*}$ & $1.68^{*}$ & $0.05^{*}$ & $3^{*}$ & $0.35^{*}$ & $0.16^{*}$ & $2^{*}$ & $1.60^{*}$ & $0.29^{*}$ & $3^{*}$ \\
\hline genistein* & $0.98^{*}$ & $0.07^{*}$ & $3^{*}$ & $1.17^{*}$ & $0.13^{*}$ & $3^{*}$ & $1.06^{*}$ & $0.11^{*}$ & $3^{*}$ & $1.09^{*}$ & $0.26^{*}$ & $3 *$ \\
\hline labetalol & 0.90 & 0.23 & 2 & n.a. & - & - & 0.45 & 0.28 & 2 & n.a. & - & - \\
\hline
\end{tabular}

${ }^{*}$ data from ref [15], n.a. - not analyzed 
Table S7. Modelled distribution ratios between cells and water $\left(D_{\text {cell/w }}\right)$ at $\mathrm{pH} 7.4$ and $37^{\circ} \mathrm{C}$ for seven different cell lines. Protein and lipid contents from reference [16] were used for HEK293T, HEK293H, HepG2, HCT116 and Me-180 cell and from reference [15] for MCF7 and H4lle cells.

\begin{tabular}{|c|c|c|c|c|c|c|c|c|c|}
\hline & HEK293T & HEK293H & HepG2 & HCT116 & Me-180 & MCF7 & H4lle & & \\
\hline Chemical & $\begin{array}{c}\log D_{\text {cell/w }} \\
{\left[L_{\text {water }} / L_{\text {cell }}\right]} \\
\text { pH 7.4, 37 } \mathrm{C}\end{array}$ & $\begin{array}{c}\log D_{\text {cell/w }} \\
{\left[L_{\text {water }} / L_{\text {cell }}\right]} \\
\text { pH 7.4, } 37^{\circ} \mathrm{C}\end{array}$ & $\begin{array}{c}\log D_{\text {cell/w }} \\
{\left[L_{\text {water }} / L_{\text {cell }}\right]} \\
\text { pH 7.4, 37 }{ }^{\circ} \mathrm{C}\end{array}$ & $\begin{array}{c}\log D_{\text {cell/w }} \\
{\left[L_{\text {water }} / L_{\text {cell }}\right]} \\
\text { pH 7.4, 37 } \mathrm{C}\end{array}$ & $\begin{array}{c}\log D_{\text {cell/w }} \\
{\left[L_{\text {water }} / L_{\text {cell }}\right]} \\
\text { pH 7.4, } 37^{\circ} \mathrm{C}\end{array}$ & $\begin{array}{c}\log D_{\text {cell/w }} \\
{\left[L_{\text {water }} / L_{\text {cell }}\right]} \\
\text { pH 7.4, 37 } \mathrm{C}\end{array}$ & $\begin{array}{c}\log D_{\text {cell } / \mathrm{w}} \\
{\left[\mathrm{L}_{\text {water }} / L_{\text {cell }}\right]} \\
\mathrm{pH} 7.4,37^{\circ} \mathrm{C}\end{array}$ & average & SD \\
\hline $\mathrm{B}[\mathrm{a}] \mathrm{P}$ & 5.08 & 5.59 & 5.56 & 5.47 & 5.52 & 4.76 & 4.85 & 5.26 & 0.36 \\
\hline $\mathrm{B}[\mathrm{k}] \mathrm{F}$ & 4.94 & 5.45 & 5.43 & 5.34 & 5.38 & 4.62 & 4.71 & 5.13 & 0.36 \\
\hline bisphenol A & 2.08 & 2.28 & 2.30 & 2.30 & 2.30 & 1.83 & 1.88 & 2.14 & 0.21 \\
\hline quinoxyfen & 3.46 & 3.89 & 3.88 & 3.80 & 3.84 & 3.16 & 3.23 & 3.61 & 0.32 \\
\hline triclocarban & 4.38 & 4.84 & 4.83 & 4.75 & 4.79 & 4.07 & 4.15 & 4.54 & 0.33 \\
\hline fluoranthene & 3.68 & 4.03 & 4.03 & 3.98 & 4.00 & 3.40 & 3.46 & 3.80 & 0.28 \\
\hline 6-gingerol & 2.12 & 2.28 & 2.31 & 2.32 & 2.32 & 1.88 & 1.92 & 2.16 & 0.19 \\
\hline 8-gingerol & 3.01 & 3.34 & 3.34 & 3.30 & 3.32 & 2.75 & 2.80 & 3.12 & 0.26 \\
\hline caffeine & 0.68 & 0.66 & 0.72 & 0.79 & 0.76 & 0.52 & 0.54 & 0.67 & 0.10 \\
\hline coumarin & 1.06 & 1.15 & 1.19 & 1.23 & 1.21 & 0.86 & 0.89 & 1.08 & 0.15 \\
\hline zingerone & 1.49 & 1.50 & 1.56 & 1.63 & 1.60 & 1.28 & 1.31 & 1.48 & 0.14 \\
\hline lamotrigine & 1.15 & 1.21 & 1.26 & 1.31 & 1.29 & 0.95 & 0.98 & 1.16 & 0.15 \\
\hline metoprolol & 0.59 & 0.64 & 0.68 & 0.72 & 0.70 & 0.44 & 0.46 & 0.60 & 0.12 \\
\hline propranolol & 1.06 & 1.38 & 1.37 & 1.33 & 1.35 & 0.82 & 0.87 & 1.17 & 0.25 \\
\hline diphenhydramine & 1.03 & 1.14 & 1.17 & 1.20 & 1.19 & 0.82 & 0.85 & 1.06 & 0.16 \\
\hline venlafaxine & 0.66 & 0.73 & 0.77 & 0.80 & 0.79 & 0.49 & 0.52 & 0.68 & 0.13 \\
\hline diclofenac & 3.33 & 3.30 & 3.38 & 3.46 & 3.43 & 3.11 & 3.14 & 3.31 & 0.13 \\
\hline $2,4-D$ & 2.49 & 2.47 & 2.54 & 2.62 & 2.59 & 2.27 & 2.30 & 2.47 & 0.13 \\
\hline ibuprofen & 2.95 & 2.92 & 3.00 & 3.08 & 3.04 & 2.73 & 2.76 & 2.93 & 0.13 \\
\hline naproxen & 4.14 & 4.11 & 4.19 & 4.27 & 4.23 & 3.92 & 3.95 & 4.12 & 0.13 \\
\hline torasemide & 2.74 & 2.72 & 2.79 & 2.87 & 2.84 & 2.52 & 2.55 & 2.72 & 0.13 \\
\hline warfarin & 2.39 & 2.37 & 2.44 & 2.52 & 2.49 & 2.17 & 2.20 & 2.37 & 0.13 \\
\hline genistein & 1.90 & 2.10 & 2.12 & 2.12 & 2.12 & 1.66 & 1.70 & 1.96 & 0.21 \\
\hline labetalol & 1.31 & 1.80 & 1.78 & 1.69 & 1.74 & 1.01 & 1.10 & 1.49 & 0.34 \\
\hline
\end{tabular}


Figure S7. Comparison of cell-water distribution ratios $\left(D_{\text {cell/w }}\right)$ of all chemicals determined for individual cell lines with the average $D_{\text {cell/w }}$ of all cell lines.

cell lines

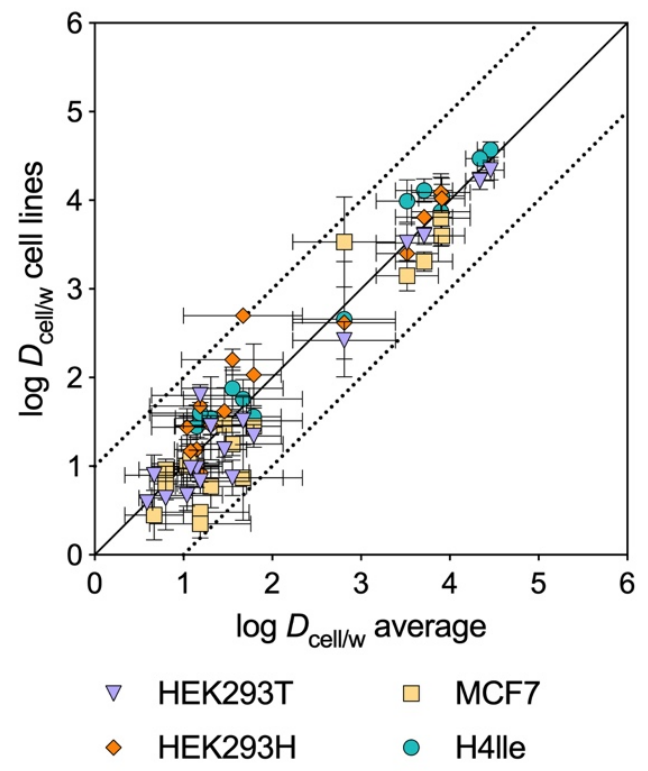

For the 13 test chemicals for which data were available for all four cell lines the Welch ANOVA test was performed to check whether there were significant differences between the different cell lines. The calculated $P$ values indicate that there was a significant difference between log $D_{\text {cell/w }}$ for the different cell lines for nine chemicals (Table S7). The Dunnett's T3 multiple comparisons test was used as post hoc test to compare the different cell lines among each other (Table S8). For five chemicals (6-gingerol, diclofenac, 2,4-D, ibuprofen and genistein) no pair of cell lines differed from each other, for seven chemicals 1-3 out of six pairs showed a significant difference and only for one chemical (coumarin) five out of six pairs of cell lines were different from each other. The mean differences between the cell lines were lower than 1 log-unit (i.e. $D_{\text {cell/w }}$ were less than a factor of ten different) for 69 out of 78 comparisons made (Table S8). The $\mathrm{P}$ values reported in Table S7 were also analyzed using the method of Benjamini and Hochberg [17] (Table S9). According to this test the difference between the different cell lines was only significant for three chemicals: torasemide, naproxen and bisphenol $A$. Coumarin was excluded for this analysis as the exact $P$ value was not known. However, the difference for coumarin was probably significant as well, because the $P$ value is $<0.0001$.

Table S8. Results of the Welch ANOVA test.

\begin{tabular}{lcc}
\hline Chemical & P value & significant? \\
\hline bisphenol A & 0.0018 & Yes \\
fluoranthene & 0.0054 & Yes \\
6-gingerol & 0.1713 & No \\
8-gingerol & 0.0087 & Yes \\
coumarin & $<0.0001$ & Yes \\
zingerone & 0.0353 & Yes \\
diclofenac & 0.0495 & Yes \\
2,4-D & 0.1261 & No \\
ibuprofen & 0.0565 & No \\
naproxen & 0.0017 & Yes \\
torasemide & 0.0007 & Yes \\
warfarin & 0.0058 & Yes \\
genistein & 0.38 & No \\
\hline
\end{tabular}


Table S9. Results of the Dunnett's T3 multiple comparisons test.

Dunnett's T3 multiple comparisons test Mean Diff. $\quad 95.00 \% \mathrm{Cl}$ of diff. Significant?

\begin{tabular}{|c|c|c|c|}
\hline \multicolumn{4}{|l|}{ bisphenol A } \\
\hline HEK293T vs. HEK293H & -0.6914 & -1.143 to -0.2396 & Yes \\
\hline HEK293T vs. MCF7 & -0.111 & -0.3522 to 0.1301 & No \\
\hline HEK293T vs. H4lle & -0.2189 & -0.4723 to 0.03445 & No \\
\hline HEK293H vs. MCF7 & 0.5803 & 0.1376 to 1.023 & Yes \\
\hline HEK293H vs. H4lle & 0.4724 & 0.02595 to 0.9189 & Yes \\
\hline MCF7 vs. H4lle & -0.1079 & -0.3098 to 0.09397 & No \\
\hline \multicolumn{4}{|l|}{ fluoranthene } \\
\hline HEK293T vs. HEK293H & -0.2085 & -0.6274 to 0.2103 & No \\
\hline HEK293T vs. MCF7 & 0.2969 & -0.1444 to 0.7382 & No \\
\hline HEK293T vs. H4lle & -0.5017 & -0.9921 to -0.01127 & Yes \\
\hline HEK293H vs. MCF7 & 0.5054 & 0.05474 to 0.9561 & Yes \\
\hline HEK293H vs. H4lle & -0.2932 & -0.8181 to 0.2318 & No \\
\hline MCF7 vs. H4lle & -0.7986 & -1.307 to -0.2906 & Yes \\
\hline \multicolumn{4}{|l|}{ 6-gingerol } \\
\hline HEK293T vs. HEK293H & -0.1992 & -1.082 to 0.6837 & No \\
\hline HEK293T vs. MCF7 & -1.11 & -3.260 to 1.040 & No \\
\hline HEK293T vs. H4lle & -0.2402 & -4.572 to 4.091 & No \\
\hline HEK293H vs. MCF7 & -0.9112 & -4.165 to 2.343 & No \\
\hline HEK293H vs. H4lle & -0.041 & -4.188 to 4.106 & No \\
\hline MCF7 vs. H4lle & 0.8702 & -1.691 to 3.431 & No \\
\hline \multicolumn{4}{|l|}{ 8-gingerol } \\
\hline HEK293T vs. HEK293H & 0.121 & -1.186 to 1.428 & No \\
\hline HEK293T vs. MCF7 & 0.3674 & -0.4599 to 1.195 & No \\
\hline HEK293T vs. H4lle & -0.4692 & -1.456 to 0.5177 & No \\
\hline HEK293H vs. MCF7 & 0.2465 & -0.8390 to 1.332 & No \\
\hline HEK293H vs. H4lle & -0.5902 & -2.134 to 0.9535 & No \\
\hline MCF7 vs. H4lle & -0.8367 & -1.757 to 0.08350 & Yes \\
\hline \multicolumn{4}{|l|}{ coumarin } \\
\hline HEK293T vs. HEK293H & 0.8701 & 0.3602 to 1.380 & Yes \\
\hline HEK293T vs. MCF7 & 1.325 & 0.7757 to 1.875 & Yes \\
\hline HEK293T vs. H4lle & 0.2343 & -0.3606 to 0.8293 & No \\
\hline HEK293H vs. MCF7 & 0.4552 & -0.04995 to 0.9603 & Yes \\
\hline HEK293H vs. H4lle & -0.6358 & -1.205 to -0.06630 & Yes \\
\hline MCF7 vs. H4lle & -1.091 & -1.726 to -0.4556 & Yes \\
\hline \multicolumn{4}{|l|}{ zingerone } \\
\hline HEK293T vs. HEK293H & -0.7753 & -1.708 to 0.1570 & Yes \\
\hline HEK293T vs. MCF7 & -0.3339 & -1.581 to 0.9128 & No \\
\hline HEK293T vs. H4lle & -0.357 & -3.775 to 3.061 & No \\
\hline HEK293H vs. MCF7 & 0.4414 & -0.6798 to 1.563 & No \\
\hline HEK293H vs. H4lle & 0.4183 & -1.791 to 2.627 & No \\
\hline MCF7 vs. H4lle & -0.02309 & -2.382 to 2.336 & No \\
\hline \multicolumn{4}{|l|}{ diclofenac } \\
\hline HEK293T vs. HEK293H & -0.4418 & -4.244 to 3.360 & No \\
\hline HEK293T vs. MCF7 & -0.2826 & -3.835 to 3.270 & No \\
\hline HEK293T vs. H4lle & -0.2861 & -3.053 to 2.481 & No \\
\hline HEK293H vs. MCF7 & 0.1592 & -0.1509 to 0.4693 & No \\
\hline HEK293H vs. H4lle & 0.1557 & -2.530 to 2.842 & No \\
\hline MCF7 vs. H4lle & -0.003444 & -2.675 to 2.668 & No \\
\hline \multicolumn{4}{|l|}{$2,4-D$} \\
\hline HEK293T vs. HEK293H & -0.2158 & -1.210 to 0.7780 & No \\
\hline HEK293T vs. MCF7 & -0.01875 & -1.372 to 1.334 & No \\
\hline HEK293T vs. H4lle & -0.4773 & -1.464 to 0.5093 & No \\
\hline HEK293H vs. MCF7 & 0.1971 & -0.7107 to 1.105 & No \\
\hline HEK293H vs. H4lle & -0.2615 & -1.338 to 0.8147 & No \\
\hline MCF7 vs. H4lle & -0.4586 & -1.968 to 1.051 & No \\
\hline \multicolumn{4}{|l|}{ ibuprofen } \\
\hline HEK293T vs. HEK293H & -0.009461 & -0.4466 to 0.4277 & No \\
\hline HEK293T vs. MCF7 & 0.6804 & -0.2901 to 1.651 & No \\
\hline HEK293T vs. H4lle & -0.08947 & -3.073 to 2.894 & No \\
\hline HEK293H vs. MCF7 & 0.6899 & -0.3214 to 1.701 & No \\
\hline HEK293H vs. H4lle & -0.08001 & -3.099 to 2.939 & No \\
\hline MCF7 vs. H4lle & -0.7699 & -2.796 to 1.257 & No \\
\hline
\end{tabular}


Table S9. continued.

\begin{tabular}{|c|c|c|c|}
\hline \multicolumn{4}{|l|}{ naproxen } \\
\hline HEK293T vs. HEK293H & -1.329 & -2.255 to -0.4034 & Yes \\
\hline HEK293T vs. MCF7 & -0.3781 & -1.308 to 0.5518 & No \\
\hline HEK293T vs. H4lle & -1.014 & -1.984 to -0.04383 & Yes \\
\hline HEK293H vs. MCF7 & 0.9512 & 0.4230 to 1.479 & Yes \\
\hline HEK293H vs. H4lle & 0.3152 & -0.7179 to 1.348 & No \\
\hline MCF7 vs. H4lle & -0.636 & -1.673 to 0.4006 & No \\
\hline \multicolumn{4}{|l|}{ torasemide } \\
\hline HEK293T vs. HEK293H & -1.19 & -1.677 to -0.7024 & Yes \\
\hline HEK293T vs. MCF7 & 0.6402 & -1.365 to 2.646 & No \\
\hline HEK293T vs. H4lle & -0.2553 & -1.031 to 0.5201 & No \\
\hline HEK293H vs. MCF7 & 1.83 & -1.214 to 4.873 & No \\
\hline HEK293H vs. H4lle & 0.9342 & -0.4637 to 2.332 & No \\
\hline MCF7 vs. H4lle & -0.8955 & -2.941 to 1.150 & No \\
\hline \multicolumn{4}{|l|}{ warfarin } \\
\hline HEK293T vs. HEK293H & -0.852 & -1.753 to 0.04898 & Yes \\
\hline HEK293T vs. MCF7 & 0.4798 & -0.9635 to 1.923 & No \\
\hline HEK293T vs. H4lle & -0.7735 & -1.999 to 0.4519 & No \\
\hline HEK293H vs. MCF7 & 1.332 & -4.497 to 7.160 & No \\
\hline HEK293H vs. H4lle & 0.0785 & -1.743 to 1.900 & No \\
\hline MCF7 vs. H4lle & -1.253 & -2.575 to 0.06778 & Yes \\
\hline \multicolumn{4}{|l|}{ genistein } \\
\hline HEK293T vs. HEK293H & -0.1846 & -0.7486 to 0.3795 & No \\
\hline HEK293T vs. MCF7 & -0.07668 & -0.5772 to 0.4238 & No \\
\hline HEK293T vs. H4lle & -0.1081 & -1.815 to 1.599 & No \\
\hline HEK293H vs. MCF7 & 0.1079 & -0.4134 to 0.6292 & No \\
\hline HEK293H vs. H4lle & 0.07651 & -1.058 to 1.211 & No \\
\hline MCF7 vs. H4lle & -0.03138 & -1.136 to 1.073 & No \\
\hline
\end{tabular}

Table S10. Results of the Benjamini and Hochberg test.

\begin{tabular}{lccc}
\hline Chemical & P value & q value & significant? \\
\hline bisphenol A & 0.0018 & 0.0072 & Yes \\
fluoranthene & 0.0054 & 0.0139 & No \\
6-gingerol & 0.1713 & 0.1869 & No \\
8-gingerol & 0.0087 & 0.0174 & No \\
zingerone & 0.0353 & 0.0605 & No \\
diclofenac & 0.0495 & 0.0743 & No \\
2,4-D & 0.1261 & 0.1513 & No \\
ibuprofen & 0.0565 & 0.0753 & Yes \\
naproxen & 0.0017 & 0.0072 & Yes \\
torasemide & 0.0007 & 0.0072 & No \\
warfarin & 0.0058 & 0.0139 & No \\
genistein & 0.3800 & 0.3800 & \\
\hline
\end{tabular}




\section{S11. Prediction of cell-water distribution using structural proteins as surrogate for cellular proteins}

Figure S8. Comparison of modelled (MBM, Fischer et al. [16]) and measured cell-water distribution ratios $\left(D_{\text {cell/w }}\right)$ of all chemicals. Structural proteins were used as surrogates for cellular proteins for the MBM predictions (see Table S11).

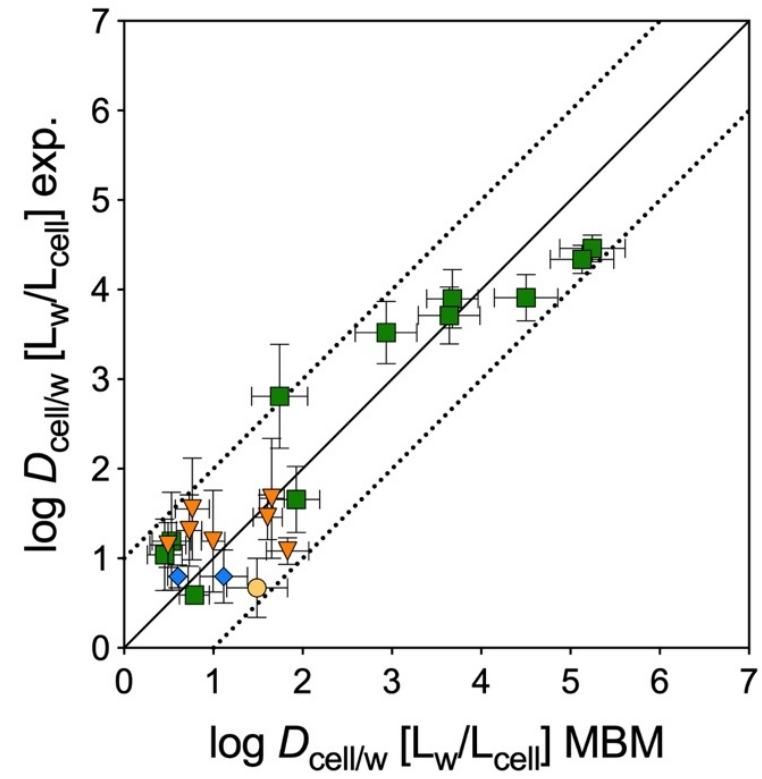

Table S11. Structural protein-water distribution ratios $\left(D_{\mathrm{SP} / \mathrm{w}}\right)$ of the test chemicals and cellwater distribution ratios predicted based on these $D_{\mathrm{SP} / \mathrm{w}}$ (average of seven cell lines as shown in Table S7).

\begin{tabular}{|c|c|c|c|c|}
\hline Chemical & $\begin{array}{c}\log D_{S P / w} \\
{\left[L_{w} / L_{\text {protein }}\right]} \\
\text { pH 7.4,37 } \mathrm{C}\end{array}$ & Reference & $\begin{array}{c}\text { average log } \\
D_{\text {cell } / \mathrm{w}}\left[\mathrm{L}_{\text {water }} / \mathrm{L}_{\text {cell }}\right] \\
\mathrm{pH} 7.4,37^{\circ} \mathrm{C}\end{array}$ & SD \\
\hline benzo[a]pyrene & 4.53 & UFZ-LSER database [18] & 5.25 & 0.36 \\
\hline benzo[k]fluoranthene & 4.88 & UFZ-LSER database [18] & 5.13 & 0.36 \\
\hline bisphenol A & 2.60 & UFZ-LSER database [18] & 1.93 & 0.26 \\
\hline quinoxyfen & 4.24 & UFZ-LSER database [18] & 3.68 & 0.29 \\
\hline triclocarban & 4.29 & UFZ-LSER database [18] & 4.50 & 0.36 \\
\hline fluoranthene & 3.67 & UFZ-LSER database [18] & 3.64 & 0.34 \\
\hline 6-gingerol & 2.07 & UFZ-LSER database [18] & 1.74 & 0.31 \\
\hline 8-gingerol & 2.97 & UFZ-LSER database [18] & 2.93 & 0.34 \\
\hline caffeine & -0.67 & UFZ-LSER database [18] & -0.03 & 0.01 \\
\hline coumarin & 0.67 & UFZ-LSER database [18] & 0.53 & 0.21 \\
\hline zingerone & 0.59 & UFZ-LSER database [18] & 0.45 & 0.19 \\
\hline lamotrigine & 1.60 & UFZ-LSER database [18] & 0.79 & 0.17 \\
\hline metoprolol & $1.51^{\mathrm{a}}$ & this study & 0.60 & 0.12 \\
\hline propranolol & 1.61 & experimental data from ref [19] & 1.12 & 0.27 \\
\hline diphenhydramine & $1.99^{a}$ & this study & 1.06 & 0.16 \\
\hline venlafaxine & $1.58^{a}$ & this study & 0.68 & 0.13 \\
\hline diclofenac & 2.60 & experimental data from ref [19] & 1.61 & 0.16 \\
\hline 2,4-D & $0.68^{b}$ & predicted using pp-LFER from ref [19] & 0.49 & 0.20 \\
\hline ibuprofen & 1.61 & experimental data from ref [19] & 0.73 & 0.14 \\
\hline naproxen & 1.46 & experimental data from ref [19] & 0.76 & 0.19 \\
\hline torasemide & $2.72^{c}$ & UFZ-LSER database [18] & 1.65 & 0.14 \\
\hline warfarin & $2.01^{d}$ & estimated from data published in ref [19] & 1.00 & 0.13 \\
\hline genistein & $2.60^{c}$ & UFZ-LSER database [18] & 1.83 & 0.24 \\
\hline labetalol & $1.24^{a}$ & this study & 1.49 & 0.34 \\
\hline
\end{tabular}

${ }^{a} \log D_{\mathrm{SP} / \mathrm{w}}$ was assumed to be equal to $D_{\mathrm{BSA} / \mathrm{w}}$, because organic bases showed similar sorption to structural proteins and serum albumin (ref [19]); ${ }^{b}$ Substance descriptors of neutral species were taken from ref [18] and used to calculate descriptors of ionic species using the eq. from ref [20] ${ }^{\mathrm{C}}$ For chemicals with significant neutral fraction at $\mathrm{pH} 7.4$ (torasemide $16 \%$, genistein $39 \%$ ), log $D_{\mathrm{SP} / \mathrm{w}}$ was assumed to the same for neutral and ionized fraction, ${ }^{d}$ Derived by: $\log D_{\mathrm{SP} / \mathrm{w}}=\log D_{\mathrm{BSA} / \mathrm{w}}-1.45$, structurally related chemicals (coumafuryl and coumachlor) showed a mean difference between $D_{\mathrm{BSA} / \mathrm{w}}$ and $D_{\mathrm{SP} / \mathrm{w}}$ of 1.45 log-units (refs [19] and [21]). 


\section{References}

1. Kosky, P.G., J.M. Silva, and E.A. Guggenheim, The aqueous phase in the interfacial synthesis of polycarbonates. Part 1. Ionic equilibria and experimental solubilities in the BPA-sodium hydroxide-water system. Industrial \& Engineering Chemistry Research, 1991. 30(3): p. 462467.

2. MacBean, C., e-Pesticide Manual. 15th ed., ver. 5.1, Alton, UK; British Crop Protection Council. Quinoxyfen (124495-18-7). 2008-2010.

3. Loftsson, T., et al., Cyclodextrin Solubilization of the Antibacterial Agents Triclosan and Triclocarban: Effect of lonization and Polymers. Journal of inclusion phenomena and macrocyclic chemistry, 2005. 52(1): p. 109-117.

4. Ishihama, Y., et al., A rapid method for pKa determination of drugs using pressure-assisted capillary electrophoresis with photodiode array detection in drug discovery. Journal of Pharmaceutical Sciences, 2002. 91(4): p. 933-942.

5. Newton, D.W. and R.B. Kluza, pKa Values of Medicinal Compounds in Pharmacy Practice. Annals of Pharmacotherapy, 1978. 12(9): p. 546-554.

6. Cessna, A.J. and R. Grover, Spectrophotometric determination of dissociation constants of selected acidic herbicides. Journal of Agricultural and Food Chemistry, 1978. 26(1): p. 289292.

7. Avdeef, A., et al., pH-Metric logP 10. Determination of Liposomal Membrane-Water Partition Coefficients of lonizable Drugs. Pharmaceutical Research, 1998. 15(2): p. 209-215.

8. Masereel, B., Torasemide Derivatives: New Perspectives. Cardiovascular Drug Reviews, 1993. 11(3): p. 359-369.

9. Ottiger, C. and H. Wunderli-Allenspach, Partition behaviour of acids and bases in a phosphatidylcholine liposome-buffer equilibrium dialysis system. European Journal of Pharmaceutical Sciences, 1997. 5(4): p. 223-231.

10. Zielonka, J., J. Gbicki, and G. Grynkiewicz, Radical scavenging properties of genistein. Free Radical Biology and Medicine, 2003. 35(8): p. 958-965.

11. Pallicer, J.M. and S.D. Kramer, Evaluation of fluorescence anisotropy to assess drug-lipid membrane partitioning. J Pharm Biomed Anal, 2012. 71: p. 219-27.

12. Vandenbelt, J.M., C. Hansch, and C. Church, Binding of apolar molecules by serum albumin. Journal of Medicinal Chemistry, 1972. 15(8): p. 787-789.

13. Endo, S. and K.U. Goss, Serum albumin binding of structurally diverse neutral organic compounds: data and models. Chem Res Toxicol, 2011. 24(12): p. 2293-301.

14. Williams, A.J., et al., The CompTox Chemistry Dashboard: a community data resource for environmental chemistry. Journal of Cheminformatics, 2017. 9(1): p. 61.

15. Henneberger, L., et al., C18-Coated Solid-Phase Microextraction Fibers for the Quantification of Partitioning of Organic Acids to Proteins, Lipids, and Cells. Chemical Research in Toxicology, 2019. 32(1): p. 168-178.

16. Fischer, F.C., et al., Modeling Exposure in the Tox21 in Vitro Bioassays. Chem Res Toxicol, 2017. 30(5): p. 1197-1208.

17. Benjamini, Y. and Y. Hochberg, Controlling the False Discovery Rate: A Practical and Powerful Approach to Multiple Testing. Journal of the Royal Statistical Society. Series B (Methodological), 1995. 57(1): p. 289-300.

18. Ulrich, N., et al., UFZ-LSER database v 3.2 [Internet]. 2017.

19. Henneberger, L., K.U. Goss, and S. Endo, Partitioning of Organic lons to Muscle Protein: Experimental Data, Modeling, and Implications for in Vivo Distribution of Organic lons. Environ Sci Technol, 2016. 50(13): p. 7029-36.

20. Abraham, M.H. and W.E. Acree, Equations for the Transfer of Neutral Molecules and lonic Species from Water to Organic phases. The Journal of Organic Chemistry, 2010. 75(4): p. 1006-1015.

21. Henneberger, L., K.U. Goss, and S. Endo, Equilibrium Sorption of Structurally Diverse Organic lons to Bovine Serum Albumin. Environ Sci Technol, 2016. 50(10): p. 5119-26. 